Review Article

\title{
New and Emerging Strategies in Platelet-Rich Plasma Application in Musculoskeletal Regenerative Procedures: General Overview on Still Open Questions and Outlook
}

\author{
Francesca Salamanna, ${ }^{1}$ Francesca Veronesi, ${ }^{1}$ Melania Maglio, ${ }^{2}$ \\ Elena Della Bella, ${ }^{2,3}$ Maria Sartori, ${ }^{1}$ and Milena Fini ${ }^{1,2}$ \\ ${ }^{1}$ Laboratory of Biocompatibility, Innovative Technologies and Advanced Therapies, Department Rizzoli RIT, \\ Rizzoli Orthopedic Institute, Via di Barbiano 1/10, 40136 Bologna, Italy \\ ${ }^{2}$ Laboratory of Preclinical and Surgical Studies, Rizzoli Orthopedic Institute, Via di Barbiano 1/10, 40136 Bologna, Italy \\ ${ }^{3}$ Department of Specialized, Experimental, and Diagnostic Medicine, University of Bologna, Via Massarenti 9, 40138 Bologna, Italy
}

Correspondence should be addressed to Francesca Salamanna; francesca.salamanna@ior.it

Received 17 August 2014; Revised 9 January 2015; Accepted 13 January 2015

Academic Editor: Tomokazu Yoshioka

\begin{abstract}
Copyright (C) 2015 Francesca Salamanna et al. This is an open access article distributed under the Creative Commons Attribution License, which permits unrestricted use, distribution, and reproduction in any medium, provided the original work is properly cited.

Despite its pervasive use, the clinical efficacy of platelet-rich plasma (PRP) therapy and the different mechanisms of action have yet to be established. This overview of the literature is focused on the role of PRP in bone, tendon, cartilage, and ligament tissue regeneration considering basic science literature deriving from in vitro and in vivo studies. Although this work provides evidence that numerous preclinical studies published within the last 10 years showed promising results concerning the application of PRP, many key questions remain unanswered and controversial results have arisen. Additional preclinical studies are needed to define the dosing, timing, and frequency of PRP injections, different techniques for delivery and location of delivery, optimal physiologic conditions for injections, and the concomitant use of recombinant proteins, cytokines, additional growth factors, biological scaffolds, and stems cells to develop optimal treatment protocols that can effectively treat various musculoskeletal conditions.
\end{abstract}

\section{Introduction}

The vulnerability of the musculoskeletal system to acute or chronic injuries is often dramatic and, according to the WHO, they are the most common causes of severe long-term pain and physical disability affecting hundreds of millions of people worldwide [1]. Thus, bone, cartilage, tendon, and ligament injuries have serious socioeconomic consequences; for example, osteoarthritis affects nearly 27 million Americans or $12.1 \%$ of the adult population of the United States with a total annual cost of about $\$ 89.1$ billion [2]. Besides osteoarthritis, also bone fracture care in osteoporotic patients has a high incidence with an annual cost of about $\$ 17$ billion [3]. Similarly, ligamentous and tendinous injuries are very common with an annual incidence estimated at about 1 per 1000 people $[4,5]$. However, the bulk of these musculoskeletal injuries does not heal with conservative managements and frequently requires surgery with several hardships for the patients. One of the most innovative methods used to biologically enhance tissue healing and regeneration includes the use of autologous blood products and, in particular, platelet-rich plasma (PRP). Blood is withdrawn from a patient's peripheral vein and centrifuged to achieve a high concentration of platelets (PLTs) within a small volume of plasma. It is reinjected at a site of injury or inserted as a gel or in combination with other biomaterials during surgery. At baseline levels, PLTs function as a natural reservoir for growth factors (GFs) and plays an important role in tissue healing and regeneration. GFs secreted by PLTs include platelet-derived growth factor (PDGF), epidermal growth factor (EGF), insulin-like growth factor (IGF-I), transforming growth factor $\beta$-I (TGF $\beta$-I), vascular endothelial growth factor (VEGF), hepatocyte growth factor (HGF), and basic fibroblast growth factor (bFGF), which provide the potential to modulate the healing of many 
TABLE 1: Main GFs release by $\alpha$-granules.

\begin{tabular}{|c|c|}
\hline GFs & Mechanism of action \\
\hline TGF- $\beta$ & $\begin{array}{l}\text { (i) MSC proliferation and differentiation } \\
\text { (ii) Cell mitogenesis } \\
\text { (iii) Collagen II, proteoglycan, and ECM synthesis } \\
\text { (iv) Endothelial chemotaxis and angiogenesis } \\
\text { (v) Macrophages and lymphocyte proliferation inhibition; chondrocyte differentiation } \\
\text { (vi) TIMP upregulation }\end{array}$ \\
\hline PDGF-a and -b & $\begin{array}{l}\text { (i) OBs and MSCs mitogenesis } \\
\text { (ii) Macrophages, neutrophil, and other cell chemotaxis; collagen I synthesis }\end{array}$ \\
\hline bFGF & $\begin{array}{l}\text { (i) Chondrocyte and OB differentiation } \\
\text { (ii) MSCs, chondrocyte, and OB mitogenesis }\end{array}$ \\
\hline EGF & $\begin{array}{l}\text { (i) Endothelial chemotaxis and angiogenesis } \\
\text { (ii) Collagen synthesis } \\
\text { (iii) MSC and epithelial cell mitogenesis }\end{array}$ \\
\hline CTGF & $\begin{array}{l}\text { (i) Angiogenesis } \\
\text { (ii) Cartilage regeneration } \\
\text { (iii) Fibrosis } \\
\text { (iv) Platelet adhesion }\end{array}$ \\
\hline VEGF & $\begin{array}{l}\text { (i) Angiogenesis } \\
\text { (ii) Endothelial cell mitogenesis }\end{array}$ \\
\hline IGF & $\begin{array}{l}\text { (i) Cell proliferation } \\
\text { (ii) Collagen synthesis } \\
\text { (iii) Myoblast proliferation and differentiation }\end{array}$ \\
\hline
\end{tabular}

tissues through interaction with specific cells $[6,7]$ (Table 1). This wide variety of GFs contributes to multifaceted roles of PRP, including the enhancement of anabolism, bone and vessel remodeling, cell proliferation, angiogenesis, inflammation control, coagulation, and cell differentiation [8].

Despite the lack of high-quality clinical trial data, several studies confirmed PRP clinical efficacy in the treatment of different types of musculoskeletal injuries [132-139]. However, many important questions remain unanswered. To reach a consensus on PRP use, there is the need of explaining why the employment of PRP generates different clinical results. The main drawback in evaluating the clinical effects of PRP is the inconsistency in established preparation protocols. To date, more than 40 commercial systems exist which claim to concentrate whole blood into a PLT-rich substance but a standardized preparation system has yet to be implemented in the common practice. Therefore, it is highly important for the clinician to be mindful of the different ways to obtain PRP and how the different methods affect the composition of PRP at the time of treatment [140]. The most important differences between the protocols and machines currently used are blood volume (from 9 to $120 \mathrm{~mL}$ ), PRP volume (from 3 to $32 \mathrm{~mL}$ ), activators $\left(\mathrm{CaCl}_{2}\right.$, thrombin, batroxobin, bovine thrombin, and thrombin added to $\mathrm{CaCl}_{2}$ ), number of spins during centrifugation (1 or 2), and PLT concentration (from $1 x$ to $18 x$ ) $[141,142]$. Additionally, the presence or absence of leukocytes, which contain considerable amounts of VEGF could further affect the quality of PRP and consequently its effects [143145]. In fact, a recent study by Kaux et al. demonstrated that a local infiltration of PRP, without both erythrocytes and leukocytes and obtained with the apheresis system, associated with submaximal eccentric protocol can improve symptoms of chronic jumper's knee [146]. Finally, the quality of PRP and resulting effects could also be influenced by patient's age, gender, body mass index, comorbidities, ethnic origin, healing capabilities, and different lifestyles (smoke, alcohol abuse, obesity, etc...) $[147,148]$.

The huge literature about this topic, from basic science reviews to in vitro and in vivo research, as well as clinical studies, highlighted the need of validated classification systems to compare the crucial differences between PRP preparation protocols. Among those proposed, we considered the PAW classification which assigns a code based on PLT concentration (PLTs/ $\mu \mathrm{L}$ ), kind of activation (endogenous/exogenous), and white blood cell concentration (total WBCs and neutrophils) [149]. This paper is planned to give an overview of the last decade on the in vitro and in vivo studies on PRP in musculoskeletal regeneration also evaluating the different preparation protocols. Bone, cartilage, tendon, and ligament regeneration was considered.

\section{Search Strategies}

To identify the studies to be considered in the current review, a PubMed database search was performed using the following MeSH: "platelet-rich plasma" and "regeneration". The searching limits were English language and papers published from July 8, 2004, to July 8, 2014. Three authors (Francesca Salamanna, Francesca Veronesi, and Melania Maglio) evaluated all articles. Studies were included if they were available online, in vitro or in vivo, and regarding bone, cartilage, tendons, and ligaments, while they were excluded if title and abstract clearly refuted eligibility. Also reviews, letters, or comments to the editor and clinical studies were 


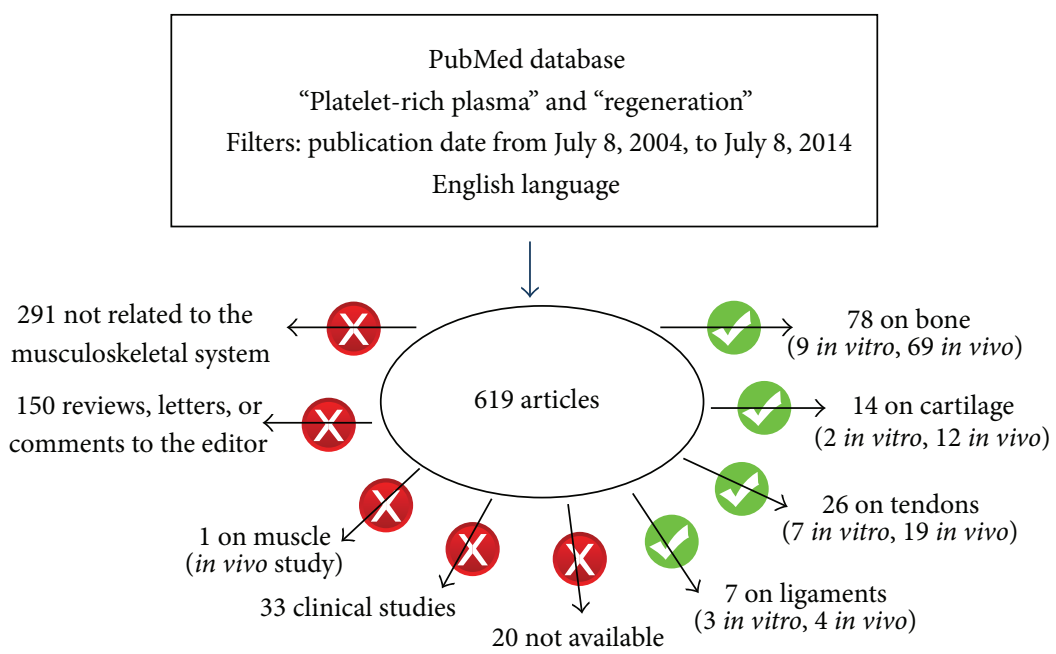

Figure 1: Schematic representation of the PubMed database searches.

excluded. All the selections were performed independently in duplicate. Disagreement was resolved by consensus.

\section{Results}

3.1. Search Strategies. The PubMed search produced 619 articles. Several studies (494) were excluded: 290 were not related to musculoskeletal system, 150 were reviews, letters, or comments to the editor, 1 was on muscle regeneration, 33 were clinical studies on musculoskeletal system, and the other 20 were not available online to us. So a total of 125 articles were analyzed (Figure 1). In Figure 2, the number of papers for each tissue and year is reported (Figure 2).

Regarding bone tissue, the reviewed in vitro studies were carried out on osteoblasts (OBs) or mesenchymal stem cells (MSCs) with PRP combined or not with scaffolds. In vivo studies were performed with PRP alone or with autologous bone/scaffolds/cells or with a combination of scaffolds and cells. For tendon tissue regeneration, the examined in vitro studies evaluated the effects of PRP alone or with MSCs and scaffold on tenocytes or tendon tissue explants. In the in vivo studies, PRP was employed alone or associated with scaffolds, cells (mainly MSCs), or their combination. Concerning the in vitro studies on cartilage, PRP alone or with scaffold was evaluated on human chondrocytes, while, in in vivo ones, PRP was used in association with scaffolds or cells (chondrocytes or MSCs), also in combination with microfractures. As for anterior cruciate ligament (ACL) reconstruction, the in vitro studies evaluated the ACL fibroblast behavior under the effect of PRP with or without scaffolds while the in vivo evaluations were performed with PRP alone or in combination with scaffolds.

The main variables found among studies under review are presented in Table 2, while all the basic science literature derived from in vitro and in vivo studies were summarized in Tables 3 and 4.

3.2. PRP Biology: What Have We Learned? Before examining PRP effects in musculoskeletal regeneration, a brief overview on its biology is provided below.

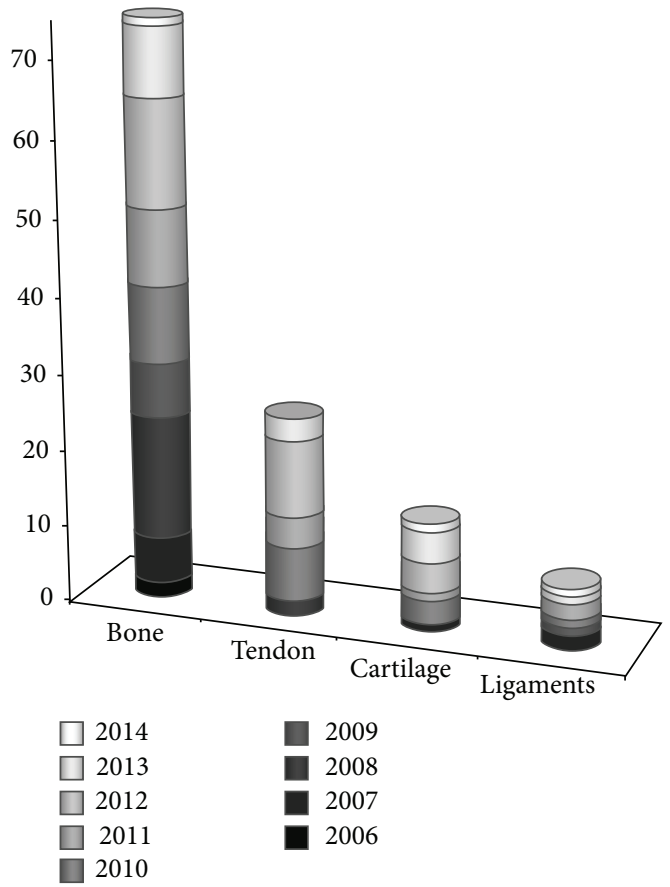

FIGURE 2: An overview on the application of PRP in musculoskeletal regenerative procedures in the last decade.

3.2.1. Terminology and PLTs Products. Even though PRP is a generic term, many definitions and acronyms have appeared to differentiate PRP constituents and state of activation but may be also increasing the confusion. Although many authors urge standardization, the variety of names unfortunately does little to help standardize the product. PRP or PRF (plateletrich fibrin) is the most used acronyms to indicate PLTs concentrates. Their processing techniques allow discarding the nonclinical useful elements, such as most of red blood cells, to concentrate the therapeutic effective ones, such as PLTs, GFs, leukocytes, or fibrinogen/fibrin. Actually, PRP 
TABLE 2: Main variables of the reviewed studies and factors implicated in PRP efficacy.

\begin{tabular}{|c|c|c|c|c|c|c|}
\hline Tissue type & Study type & $\begin{array}{l}\text { Blood volume } \\
(\mathrm{mL})\end{array}$ & $\begin{array}{l}\text { PRP volume } \\
(\mathrm{mL})\end{array}$ & $\begin{array}{c}\text { PLT count } \\
\left(\times 10^{6} / \mu \mathrm{L} \text { PRP }\right) \\
\end{array}$ & $\begin{array}{l}\text { Leukocyte count } \\
\qquad\left(\times 10^{4} / \mu \mathrm{L}\right)\end{array}$ & Activators \\
\hline \multirow[b]{2}{*}{ Bone } & In vitro & $51 \pm 30(n=4)$ & $5.3 \pm 6.6(n=2)$ & $4.2 \pm 6.6(n=4)$ & NS & $\begin{array}{l}\text { Thrombin, } \mathrm{CaCl}_{2}, \\
\text { Ca-gluconate }(n=4)\end{array}$ \\
\hline & In vivo & $77 \pm 135(n=54)$ & $2.6 \pm 4.9(n=34)$ & $2.3 \pm 2.3(n=34)$ & $1.4 \pm 4.1 / \mu \mathrm{L}(n=3)$ & $\begin{array}{c}\text { Thrombin, } \mathrm{CaCl}_{2} \text {, } \\
\mathrm{CaCl}_{2}+ \\
\text { thromboplastin, } \\
\mathrm{Ca} \text {-gluconate, and } \\
\mathrm{CaCl}_{2}+\text { thrombin }(n \\
=52)\end{array}$ \\
\hline \multirow[t]{2}{*}{ Tendon } & In vitro & $93 \pm 167(n=8)$ & $4.5 \pm 3.8(n=6)$ & $1.9 \pm 2.4(n=10)$ & $4 \pm 4.1 / \mu \mathrm{L}(n=2)$ & $\begin{array}{c}\text { Thrombin, } \mathrm{CaCl}_{2} \text {, } \\
\text { Ca-gluconate }+ \\
\text { thrombin }(n=5)\end{array}$ \\
\hline & In vivo & $17 \pm 16(n=15)$ & $2.4 \pm 1.2(n=9)$ & $1.9 \pm 1.6(n=9)$ & $2 \pm 3 / \mu \mathrm{L}(n=2)$ & $\begin{array}{c}\text { Thrombin, } \mathrm{CaCl}_{2}(n= \\
6)\end{array}$ \\
\hline \multirow[b]{2}{*}{ Cartilage } & In vitro & $115 \pm 61(n=3)$ & $1.0 \pm \mathrm{n} / \mathrm{a}(n=1)$ & $0.9 \pm \mathrm{n} / \mathrm{a}(n=1)$ & NS & Thrombin, $\mathrm{CaCl}_{2}$ \\
\hline & In vivo & $25 \pm 20(n=11)$ & $3.1 \pm 3.8(n=8)$ & $2.8 \pm 3.9(n=8)$ & NS & $\begin{array}{l}\text { Thrombin, } \mathrm{CaCl}_{2} \text {, } \mathrm{Ca} \text {, } \\
\text { Fibrinogen Thrombin } \\
(n=4)\end{array}$ \\
\hline \multirow{2}{*}{$\begin{array}{l}\text { Anterior cruciate } \\
\text { ligament }\end{array}$} & In vitro & $33 \pm 38(n=2)$ & NS & $0.5 \pm 0.2(n=3)$ & NS & \multirow{2}{*}{$\begin{array}{c}\text { NS } \\
\text { Thrombin, } \mathrm{CaCl}_{2}(n= \\
1)\end{array}$} \\
\hline & In vivo & $33 \pm 23(n=3)$ & $5.0 \pm 5.7(n=2)$ & $1.6 \pm 0.7(n=5)$ & NS & \\
\hline
\end{tabular}

$n$ : number of data available for the specific variable in the considered papers; NS: not specified.

products are divided into 4 families, based on leukocytes and fibrin content: pure platelet-rich plasma (P-PRP), leukocyteand platelet-rich plasma (L-PRP), pure platelet-rich fibrin (PPRF), and leukocyte- and platelet-rich fibrin (L-PRF) [150]. The first, also known as plasma rich in growth factors (PRGF), and the second are usually in the form of gel or liquid and are characterized by a low-density fibrin network, without or with leukocytes, respectively. On the other hand, the third, also named platelet-rich fibrin matrix (PRFM), and the fourth contain high-density fibrin network and exist only in the gel form. P-PRF is without leukocytes, while L-PRF contains leukocytes. It is clear that these four variables alone allow many possible variants of PRP to be produced; however, they provide a simple baseline for comparison.

3.2.2. PLTs Number and $\alpha$-Granule Contents. In healthy humans, the average PLT concentration of whole blood is around $200,000 / \mu \mathrm{L}$ (normal range 150,000 to $350,000 / \mu \mathrm{L}$ ) [151]. PLTs are small anucleated cytoplasmic fragments of megakaryocytes normally thought as the responsible agents for hemostasis. Not only are the PLTs central to the clotting cascade, but they are also fundamental to tissue healing. The first step of the healing process is clot formation and PLTs activation [151]. Then biologically active molecules, GFs, and differentiation factors, are released from the $\alpha$-granules $[152,153]$. About $70 \%$ of the GFs are secreted within the first 10 minutes next to activation and, within the first hours, almost $100 \%$ have been secreted [154]. According on where they are in course of their life, several PLTs will die within a few days while some others may last up to 9 days ongoing to generate further GFs [155]. As previously mentioned, the degranulation of $\alpha$-granules result in the release of a number of GFs, such as PDGF, EGF, IGF-I, TGF $\beta$-I, VEGF,
HGF, and bFGF (Table 1). However, other bioactive factors, which include adhesive proteins, clotting and fibrinolytic factors and their inhibitors, proteases and antiproteases, antimicrobial proteins, and membrane glycoproteins, are getting increased attention in the last decade [153]. Another aspect is that $\alpha$-granules also contain monocytes mediators and different interleukins (ILs) and chemokines, such as IL$1 \beta$, IL-8, and MIP-1-2-3, regulated on activation, normal $\mathrm{T}$ cells expressed and secreted (CCL5), and more others, which are capable of mediating inflammation, stimulate cells chemotaxis, proliferation, and maturation $[153,156,157]$.

Although PLTs have now been shown to store and release such a wide range of biologically active proteins, different enigmas, regarding their contents and possible activities on tissue healing, still remain to be solved.

3.2.3. Methods of PRP Activation. Different methods of activating PRP influence the concentration of GFs. PRPs are frequently activated by calcium chloride, thrombin, chitosan, and batroxobin. Calcium chloride and thrombin activation are the two most common methods; $5 \%$ calcium chloride treatment for 19 min produces the most effective PRP, which has properties for soft-tissue adhesion [158]. Chitosan can be used instead of thrombin because it enhances aggregation, adhesion, and expression of $\alpha$-granule membrane glycoprotein. Some data, however, suggest that exogenous thrombin activation of PRP may actually diminish its ability to induce bone formation compared with nonthrombin-activated PRP [159].

3.2.4. Inter- and Intraspecies Variability. Preclinical models offer fundamental basis for the development of clinical 


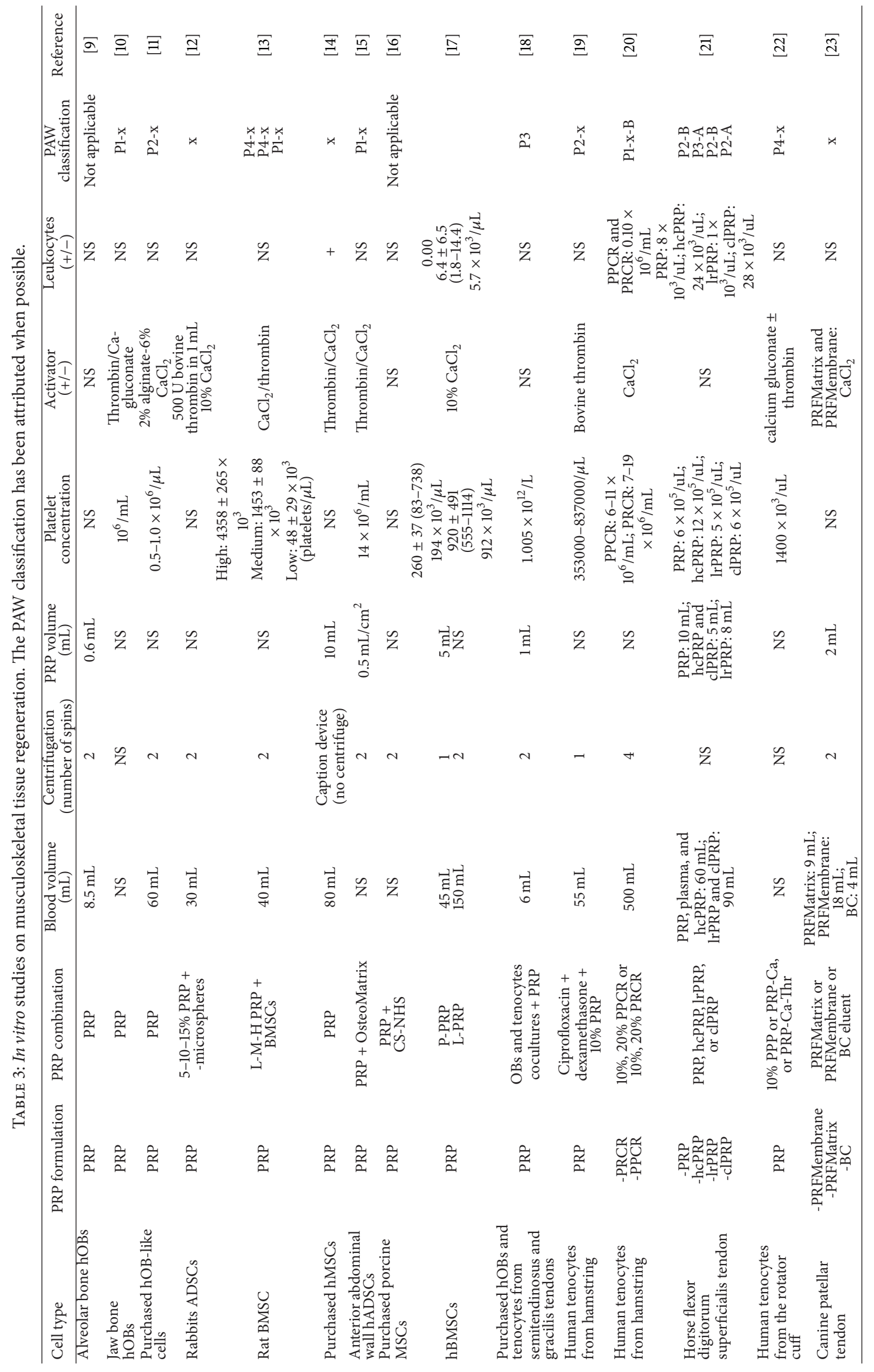




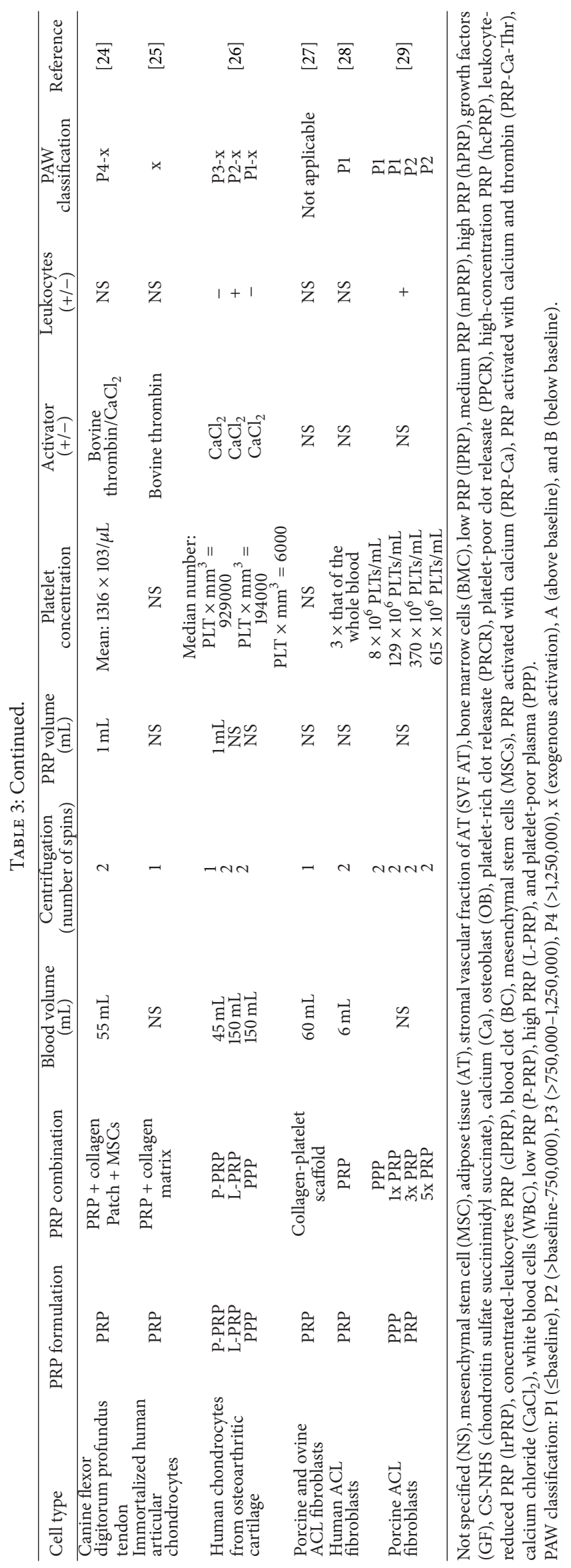




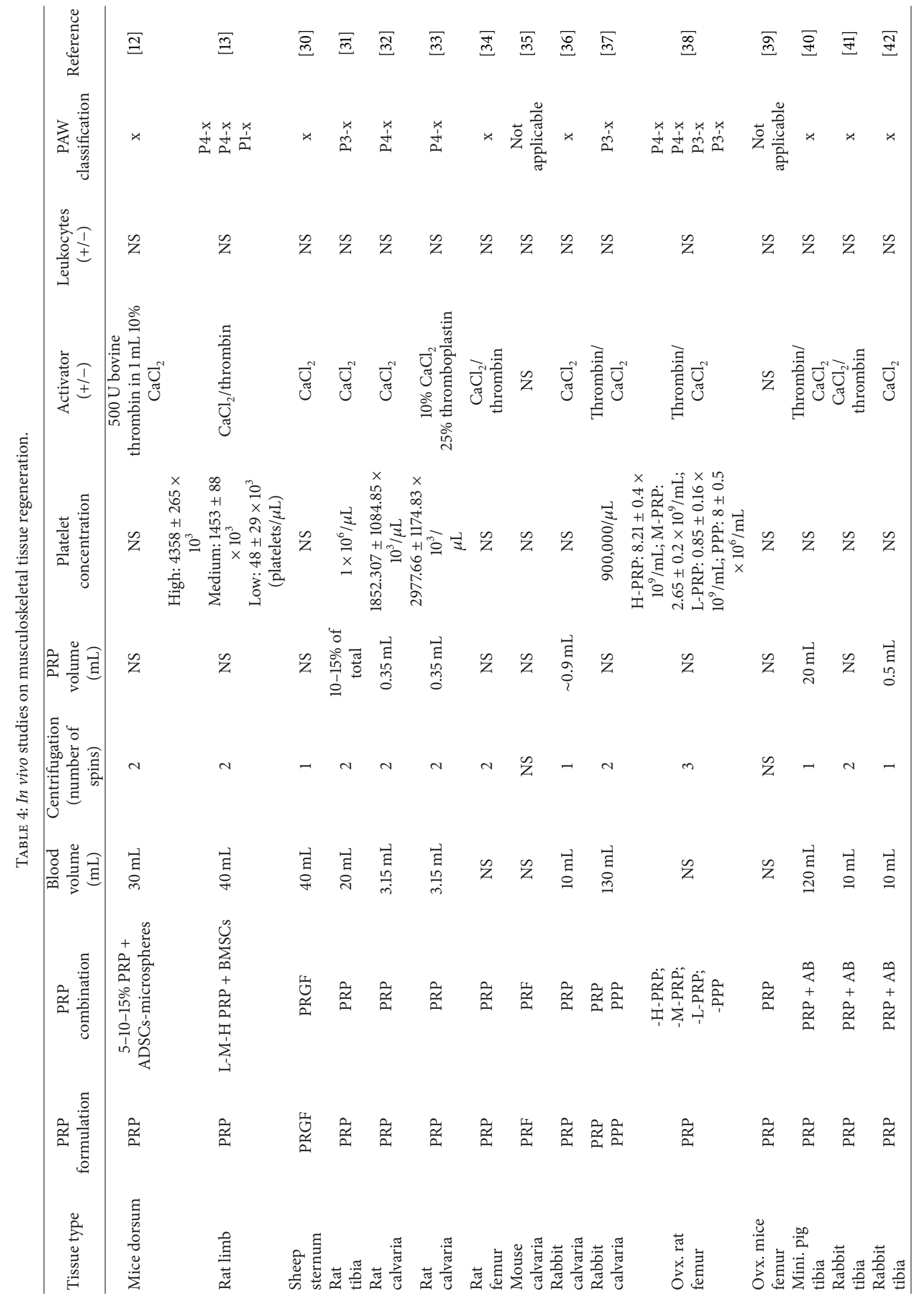




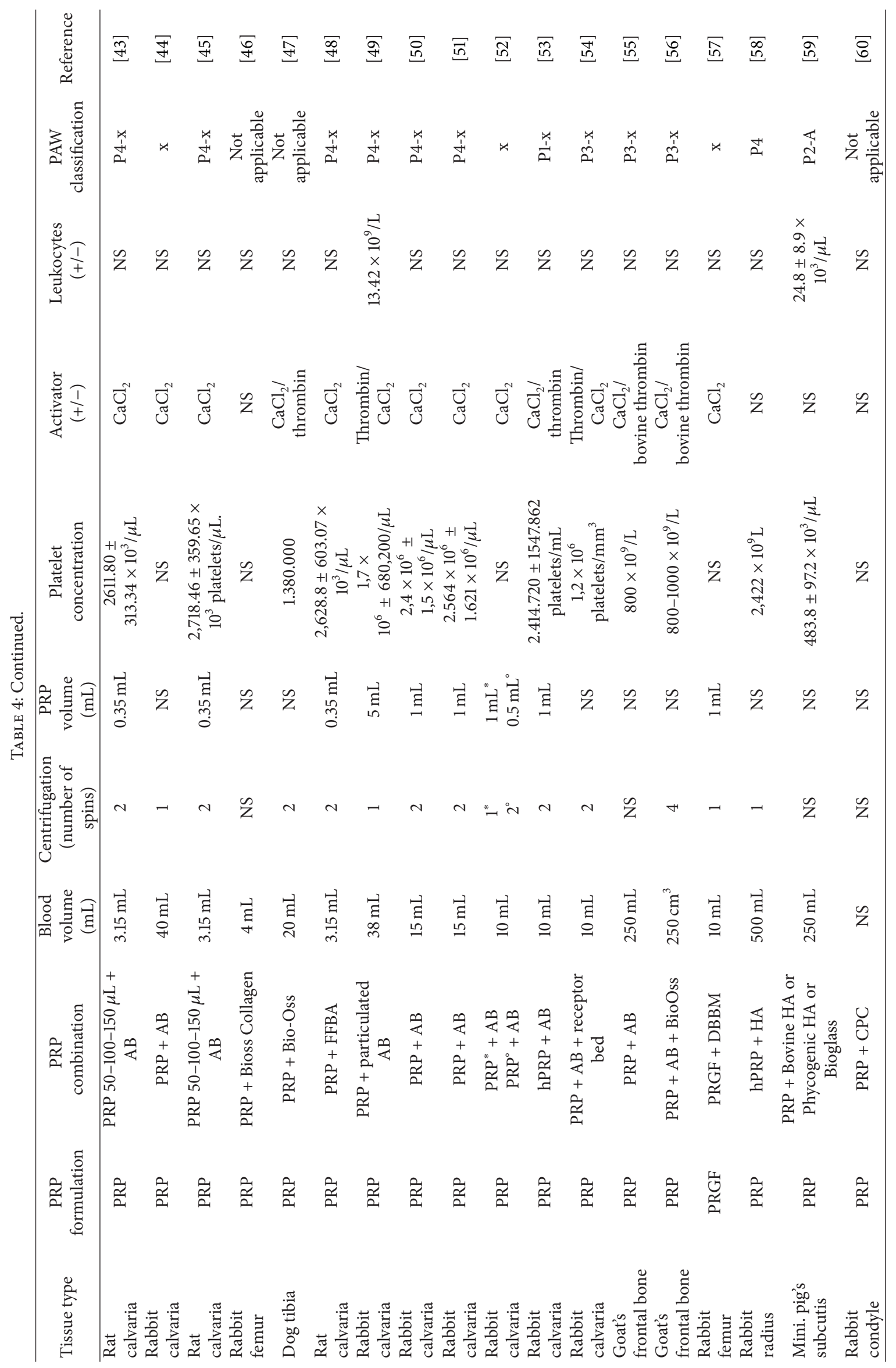




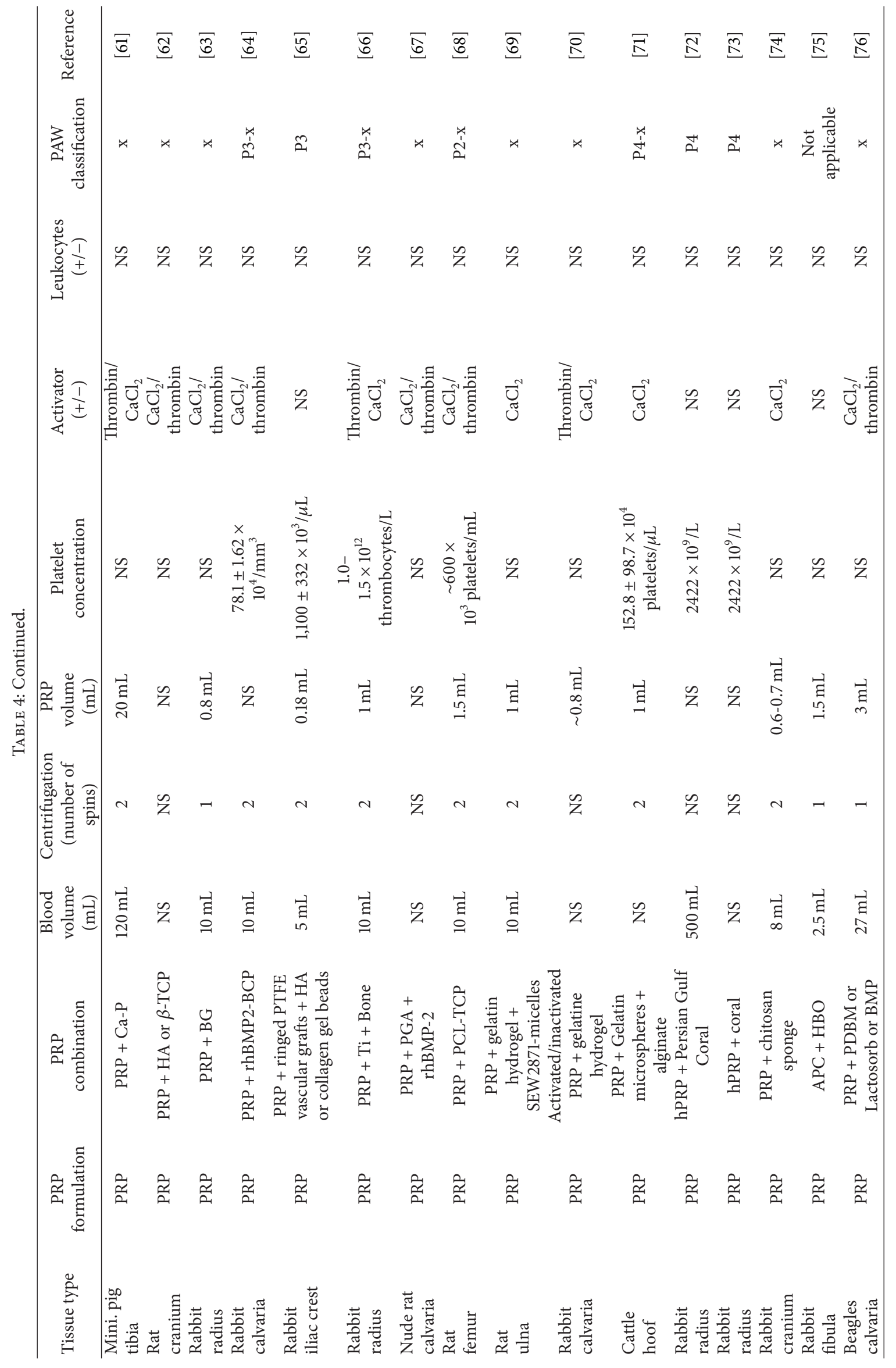




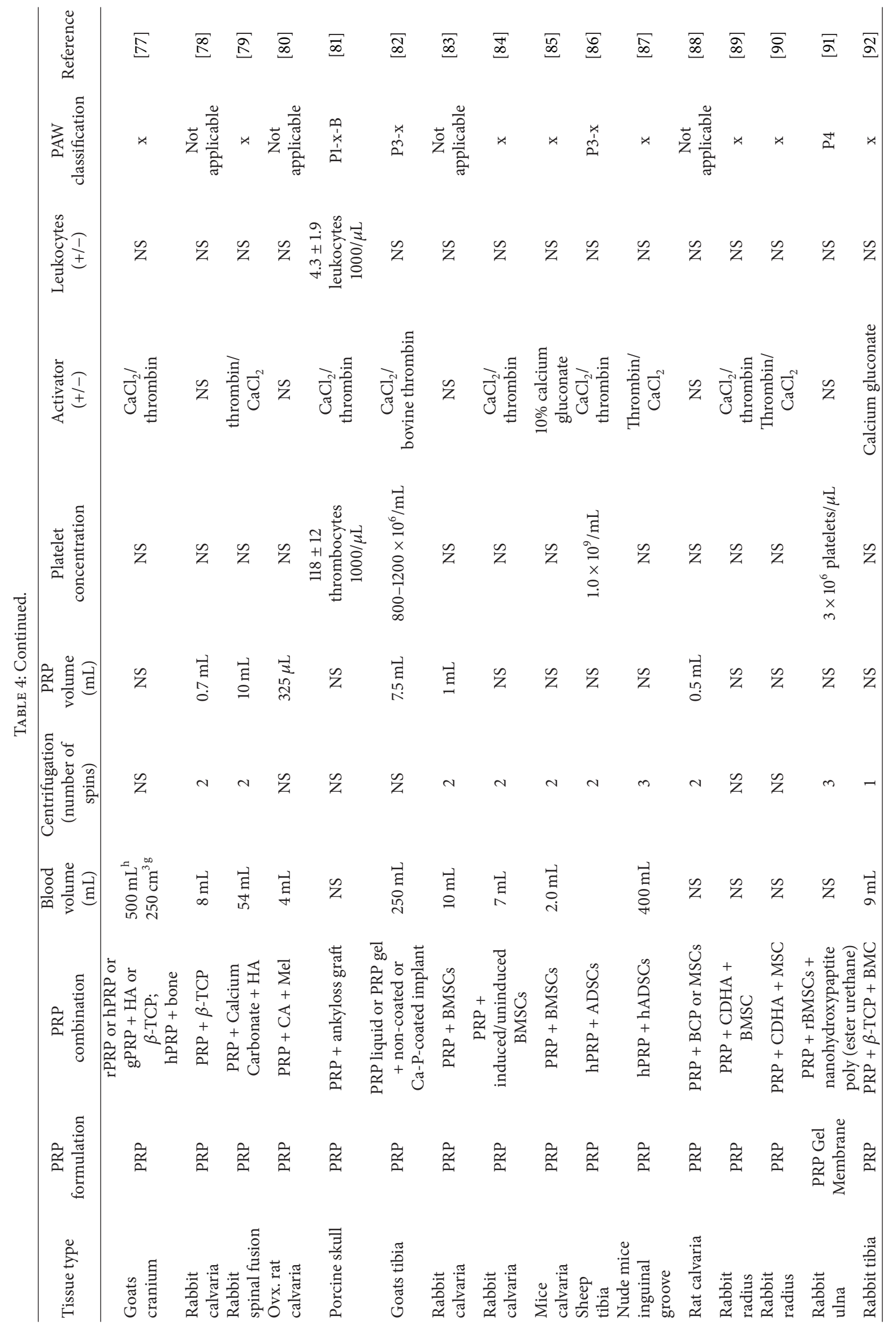




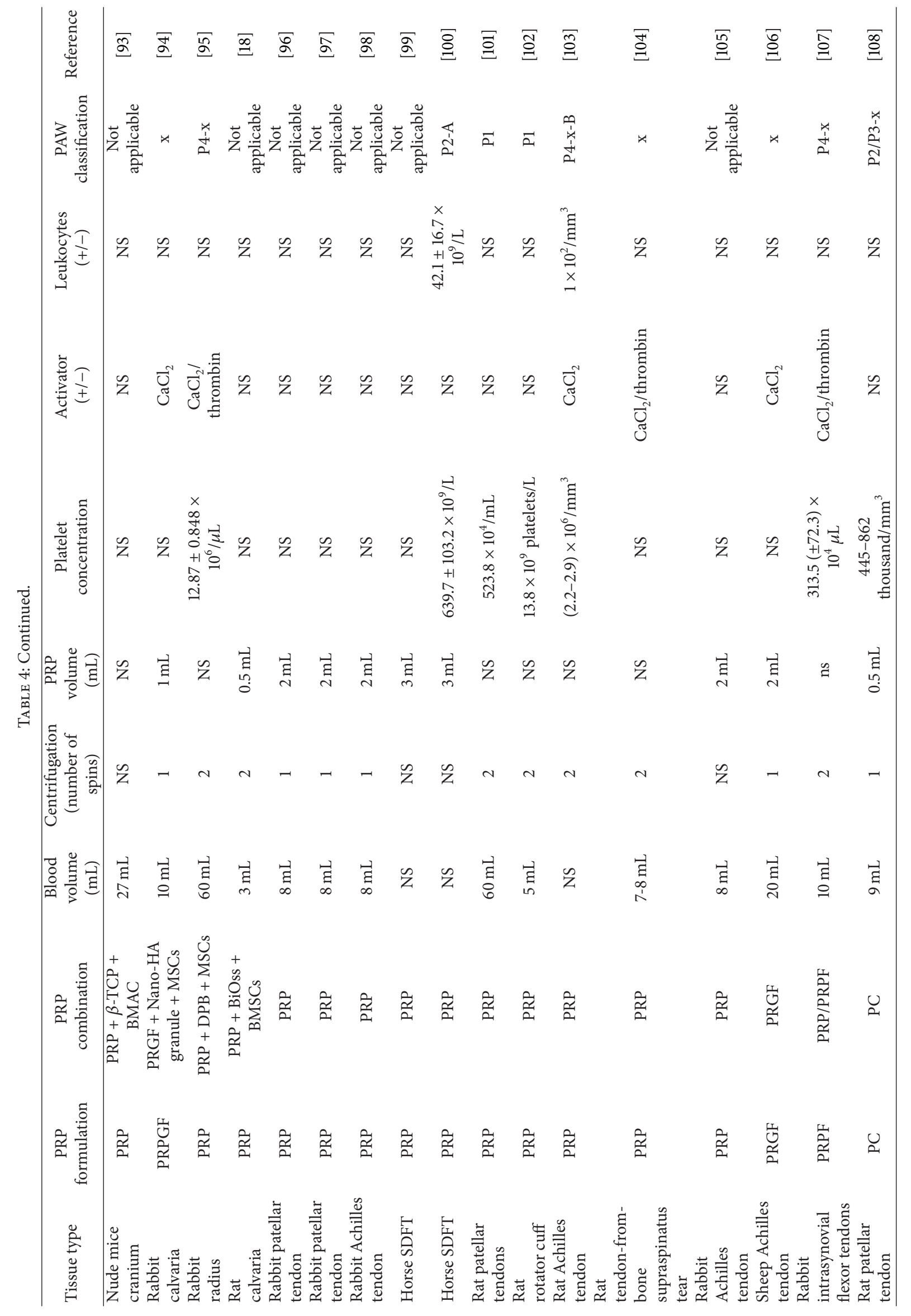




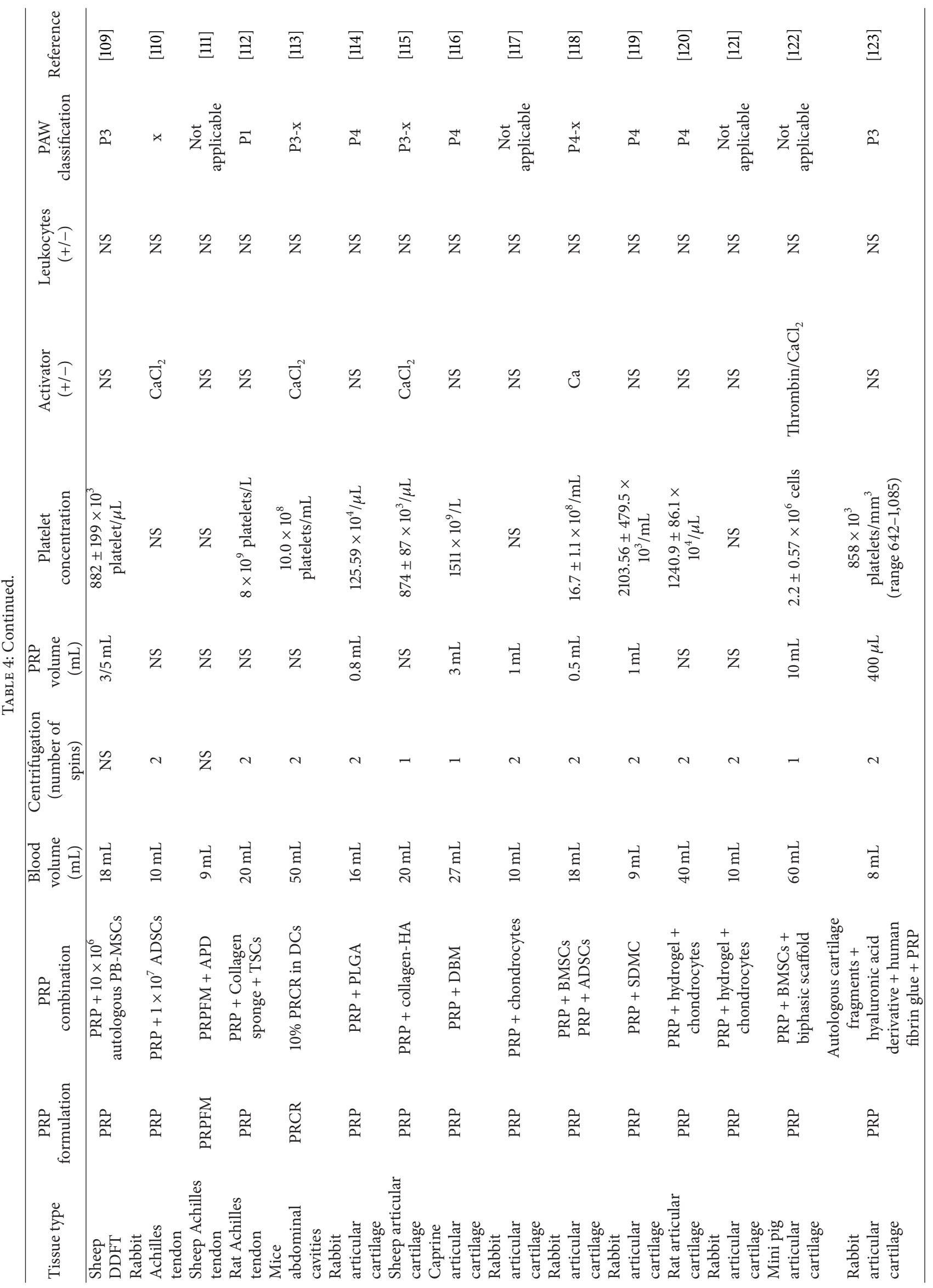




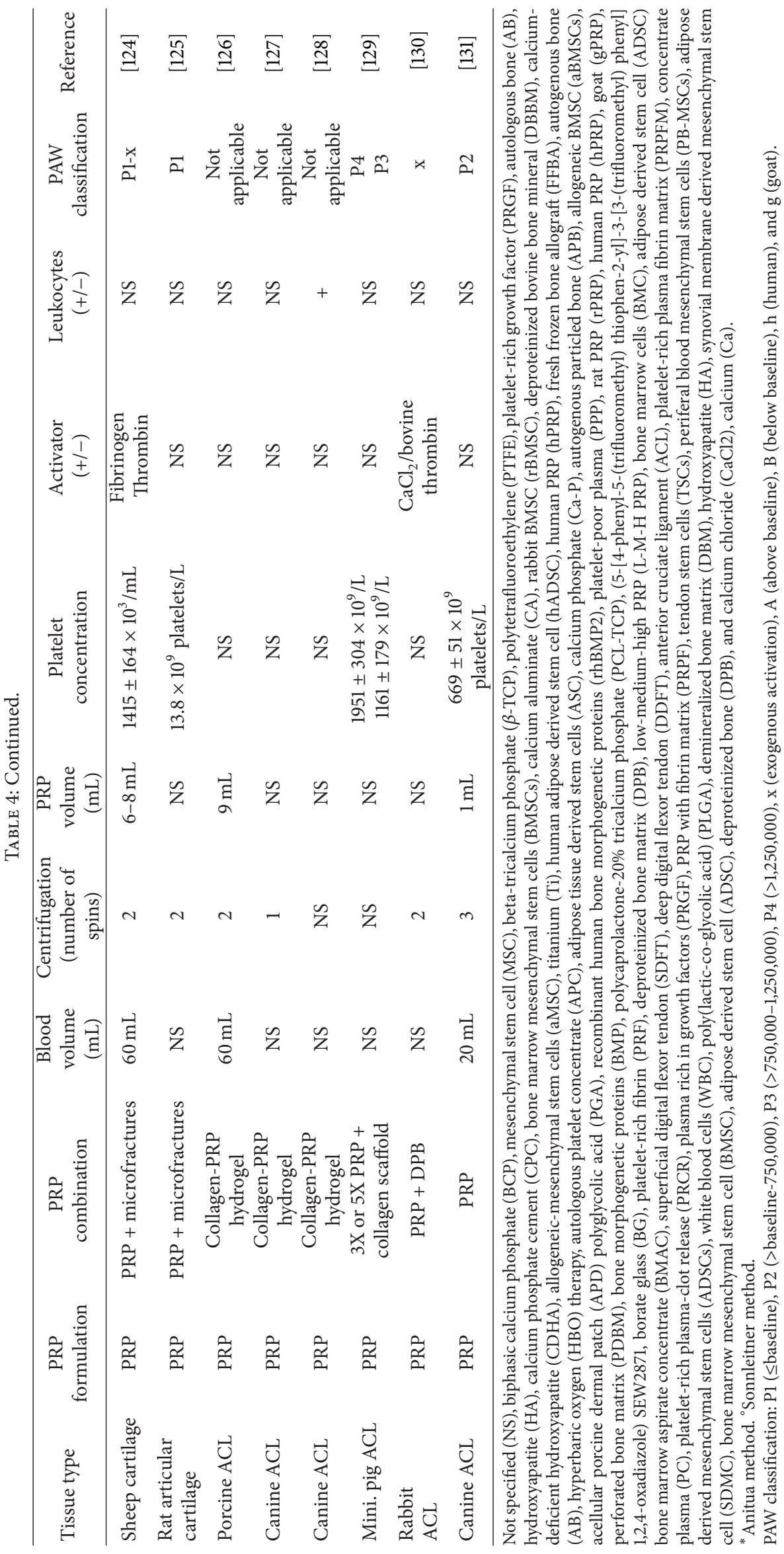


treatments, although it is necessary to consider inter- and intraspecies variability principally in terms of PLTs count. As reported by Mitruka and Rawnsley [160] each species has its own number of PLTs, also with a wide range within the same species. Thus, the knowledge of the exact number of PLTs, when an animal model is used, is fundamental for understanding the effectiveness of the PRP application. Additional variability is added by some species-specific peculiarities [148]. This important variability needs to be considered in evaluating results from different animal models because it could be one of the reasons for dissimilar results obtained when PRP is used, as also demonstrated by the studies described below.

3.2.5. Safety Profile. It is well known that PRP derive from autologous blood and this implies minimal risks for disease transmission, immunogenic reactions, and cancer [161]. GFs act on cell membranes rather than on the cell nucleus and activate normal gene expression [161]; they are not mutagenic and act through gene regulation and normal wound healing feedback control mechanisms.

Considering the long-term clinical experience with the use of PRP in oral and maxillofacial field, its use is considered to be safe $[162,163]$. Differently, no long-term studies with PRP exist in the musculoskeletal field, despite a large number of treated patients [164]. Recently, a nonrandomized, prospective, longitudinal study on 808 patients indicated no adverse effects following injection of PRGF into the knee joint at 6 months [165]. Contrary, a recent case report reported an exuberant inflammatory reaction after 1 injection of PRP to treat jumper's knee in a 35-year-old male type 1 diabetic patient, revealing that PRP should be proposed only after careful consideration in cases of patients with morbidity risks [146]. Although the adverse effects are unusual, as with any injection, there is always a slight risk of injection site morbidity, infection, or injury to nerves or blood vessels. Scar tissue formation and calcification at the injection site are remote risks [166]. Infrequently, development of antibodies against clotting factors $\mathrm{V}$ and IX leading to life threatening coagulopathies has been reported $[161,167]$. To date, no convincing preclinical studies and clinical trials demonstrating systemic effects following local PRP injections are reported and, as showed by Dhillon et al., this is probably due to the limited need of PRP injections in clinics and the short in vivo half-lives and local bioavailability of GFs produced by PRP [168].

\section{The Role of PRP in the Regeneration of Bone}

4.1. In Vitro Studies. Several studies [9-13] evaluated the in vitro effect of PRP showing that it was able to induce proliferation and osteogenic activity of human OB and OBlike cells. Additionally, Parsons et al. [14] investigated the effect of PRP on the osteogenic potential of human MSCs, suggesting the promotion of $\mathrm{OB}$ differentiation.

Bukharova et al. [15] developed a construct using a highly purified bone matrix as scaffold and osteogenic committed human adipose derived stem cells (ADSCs) together with
PRP, later activated with thrombin/calcium chloride $\left(\mathrm{CaCl}_{2}\right)$. While giving no real clues on the effect of PRP, the paper showed the creation of a construct that may be suitable for bone tissue engineering. Finally, Simson et al. [16] detected that the combination of an injectable chondroitin sulfate tissue adhesive and PRP with human MSCs could support bone growth.

More recently, Perut et al. [17] investigated the efficacy of different components of PLT concentrates on the osteogenic differentiation of BMSCs. Comparing two different procurement techniques, the authors reported that, in addition to the differences in PLT recovery between systems, the composition of PRP was associated with variance in the progressive release of bFGF from the platelet gel, which is associated with the proliferation of BMSCs and their ability to mineralize. The authors concluded that the ability of different PLT gels to induce proliferation and osteogenic differentiation of BMSCs was related to the composition of PRP including the platelet, leukocyte, and GF concentrations and availability.

At a Glance. (1) PRP addition in culture medium of MSCs, both BMSCs and ADSCs, and OBs improved proliferation and osteogenic activity; (2) the ability of different PLT gels to induce proliferation and osteogenic differentiation of BMSCs was related to the PRP composition (Table 3).

4.2. In Vivo Studies. Clots of PRP, PLT-rich GF (PRGF), and PLT-rich fibrin (PRF) were studied in different experimental conditions (sheep sternal wounds, critical size defect in rat calvaria, tibia and femurs, and nude mice calvaria bone defect) with good results in terms of bone regeneration [3035] and promotion of the expression of TGF- $\beta$ and bone morphogenetic protein-2 (BMP-2) [34]. Additionally, Messora et al. [33] observed a better outcome for PRP activated by $\mathrm{CaCl}_{2}$ in comparison to PRP activated by thromboplastin. Contrary to the above mentioned studies, Torres et al. [36] showed no beneficial effect of PRP on osseous regeneration in rabbit calvaria. Regarding the effect of topical application of PRP and platelet-poor plasma (PPP), it was compared in a rabbit model of full thickness calvaria defects, noticing better results for PRP [37]. Two studies focused on the application of PRP in osteoporosis [38, 39]. Chen et al. [38] administered different concentrations of PRP to promote the healing in osteoporotic rat femur. The results highlighted that, if on the one hand PRP enhanced bone regeneration, on the other hand too high concentrations could prevent a complete healing. Interestingly, Liu et al. [39], instead, used PRP to demonstrate its ability to prevent and treat osteoporosis by controlling the ratio of osteoblast and adipocyte in ovariectomized female mice. The study detected that PRP treatment improved bone quality in osteoporotic mice via promoting osteogenesis while suppressing adipogenesis in the bone marrow.

PRP was also added to autografts [40-45], Bio-Oss [46, 47], and fresh frozen bone allograft [48] in different animal models (i.e., critical size defects in mini. pigs, rat calvaria, and rabbit femur and tibia) and improved bone regeneration. In addition, Nagata et al. [44] explored the influence that the different proportion between particulate autogenous bone 
grafts and PRP $(50,100,150 \mu \mathrm{L})$ could exert on rat calvaria healing. The dose of $100 \mu \mathrm{L}$ of PRP proved to be the most effective in promoting bone formation, while the inhibitory effect of the highest PRP doses was noticed. However, other authors, using various animal models, found no benefits when PRP was added to autologous bone [49-53], autologous bone and Bio-Oss [55, 56], and xenografts [57].

Besides the use of PRP in combination with autografts, allografts, or xenografts, numerous studies have focused their attention on the PRP association with other synthetic and biologic materials such as ceramics (hydroxyapatite, HA, bioglass, calcium phosphate, $\mathrm{CaP}$, and beta-tricalcium phosphate $(\beta$-TCP) $)$ [58-65], metals [66], polymers (polyglycolic acid (PGA)) [67], composites (polycaprolactone-20\% tricalcium phosphate (PCL-TCP)) [68], hydrogels [69, 70], alginate [71], coral [72, 73], and chitosan [74]. The majority of studies obtained good outcomes regarding the bone regenerative potential when PRP was added to the above mentioned materials [58-74]. Additionally, a significant bone formation was observed when PRP was used with biphasic $\mathrm{CaP}$ or PGA containing BMP-2 [64, 67]. A different application was proposed by Paulo et al., which treated rabbit fibula fracture with PRP and daily hyperbaric oxygen therapy sessions, with promising results [75]. However, several studies found opposite outcomes [76] compared to those just quoted, in particular, when PRP was used in association with ceramic [77-80], metallic [81], or composite materials [82]. A work by Clafshenkel et al. [80], exploring the association of melatonin-calcium aluminate scaffold with the addition of PRP in an ovariectomized rat model of calvaria defect, explained the failure in promoting bone regeneration with a possible conflict between the proliferative thrust induced by PRP and the differentiative stimuli mediated by melatonin.

Newly formed bone in rabbit [83, 84] and mice [85] calvaria defects were also obtained using PRP and bone marrow mesenchymal stem cells (BMSCs). Niemeyer et al. [86], also using a large animal model, observed that the presence of PRP could in part balance the differences in osteogenic potential of BMSCs and ADSCs. Kawasumi et al. [13], instead, evaluating PRP with increasing concentration of PLTs in combination with BMSCs in rat limb-lengthening model, detected a better qualitative regeneration of bone tissue using the higher PRP concentration. Lastly, Liu et al. [87], also in a study on heterotopic site of nude mice, testing a novel injectable tissue-engineered bone combined with induced hADSCs resuspended in PRP, showed an improvement in bone formation.

Comparing the contribution of MSCs and PRP to the regenerative capacity of ceramic bone substitutes, several studies indicated that the combined use of the three elements got better results in terms of osteogenesis [88-91]. Additionally, Kasten et al. [89] showed that over the positive effect of PRP with MSC and ceramic material on bone healing, an effect on vascularization was also proven. Batista et al. [92], instead, proved the effectiveness in the repair of rabbit tibial defects of PRP compared to bone marrow concentrate added separately to $\beta$-TCP scaffold, while Zhong et al. [93] obtained comparable results between PRP and bone marrow aspirate concentrate in combination with $\beta$-TCP in nude mice.
Additionally, Behnia et al. [94] combined PRGF with a scaffold designed as carrier for GFs and stem cells, proving not only the applicability of the material but also the good potentiality in promoting bone regeneration when combined with PRGF and MSC. Man et al. [12] also tested the angiogenic and osteogenic potential of alginate microspheres combined with ADSCs and increasing percentage of PRP, demonstrating a high rate of mineralization in a model of nude mice with the presence of new vessel formation, with 10 and $15 \%$ of PRP. Finally, Zhang et al. [95] evaluated the immunogenicity of allogeneic PRP and the effect of a construct of allogeneic PRP/deproteinized bone matrix/autologous MSCs, with promising results not only regarding immunity but also for bone healing and vascularization. Contrary to the above mentioned study, Khojasteh et al. [169] evaluated the different contribution of PRP and BMSCs to various materials in rat calvaria defect, observing better bone formation with BMSCs alone as compared to their combination with PRP.

At a Glance. (1) Clots of PRP, PRGF, and PRF improved bone regeneration, promoting expression of TGF- $\beta$ and $\mathrm{BMP}-$ 2; (2) topical application of PRP showed better results in comparison to PPP; (3) PRP in osteoporotic animal models promoted bone healing; (4) PRP addition to autografts, BioOss, fresh frozen bone allografts, or other synthetic and biologic materials showed discordant results in term of bone healing; (5) PRP in association with BMSCs or ADSCs, also in combination with different materials, showed good bone regeneration (Table 4 ).

\section{The Role of PRP in the Regeneration of Tendons}

5.1. In Vitro Studies. Several in vitro studies observed good results with different PRP formulations or PRP associated with scaffolds and BMSCs on tenocytes or tendon culture explants. It was observed that the addition of PRP to the culture medium counteracted the inhibition of tenocytes viability and proliferation induced by the osteoblasts-tenocytes coculture system [18] or by ciprofloxacin or dexamethasone [19]. In addition, some studies compared different PRP formulations. Platelet-poor clot releasate (PPCR) or leukocyte-reduced PRP (lrPRP) showed better results than platelet-rich clot releasate (PRCR) or high-concentration PRP (hcPRP), respectively. Indeed PPCR or lrPRP increased DNA content and total collagen and decreased VEGF-A, TGF- $\beta 1$, metalloproteinases (MMP) expression [20], and proinflammatory cytokines in tenocytes or flexor digitorum superficialis tendon explants [21].

It was also observed that the best results were found in tenocytes with PRP gel activated with calcium and thrombin (PRP-Ca-Thr) in comparison to that activated with calcium (PRP-Ca) [22] and after the addition of PRFMembrane eluent in comparison to PRFMatrix ones in tenocytes medium [23].

The addition of PRP to collagen patch seeded with BMSCs improved biomechanical and histological features of digitorum profundus tendon in in vitro repair model [24]. 
At a Glance. PRP added to the culture medium of tenocytes or tendon explants improved viability and proliferation (Table 3).

5.2. In Vivo Studies. The effects of PRP alone were evaluated in acute lesions of rat supraspinatus, horse superficial digital flexor, rat rotator cuff, rat patellar, rabbit intrasynovial flexor, and sheep and rat Achilles tendons. An improvement in biomechanical, collagen fiber orientation, metabolic activity properties, and extracellular matrix (ECM) gene expression and a decrease in inflammatory cell number, vascularity, IGF-1, and TGF- $\beta$ were observed [96-105]. In addition, platelet-rich growth factor (PRGF) and PRP with fibrin matrix (PRPF) showed the same results $[106,107]$. On the contrary, no significant improvements were observed after the injection of PLT concentration (PC) in patellar tendons [108].

Also the combinations of PRP formulations with cells or scaffolds were studied. No synergic effect on sheep digital flexor healing was shown, when PRP was combined with peripheral blood MSCs (PBMSCs) [109]. On the other hand, the best results were observed when PRP was combined with ADSCs [110] or platelet-rich plasma fibrin matrix (PRPFM) with cross-linked acellular porcine dermal patch (APD), respectively, in rabbit and sheep Achilles tendon lesions [111, 130].

The use of PRP, collagen sponge, and tendon stem cells (TSCs) improved histological parameters and Coll I and Coll III expressions and productions of rat Achilles tendon lesions, especially after physical activity [112].

Finally, after the injection into mice abdominal cavities, tenocytes precultured with platelet-rich plasma-clot release (PRCR) induced high collagen production and tenocyte markers expression [113].

At a Glance. (1) On tendon lesions, PRP improved biomechanical, collagen fibers orientation, metabolic activity properties, and ECM gene expression with a decrease of inflammatory cell number, vascularity, IGF-1, and TGF- $\beta$; (2) PRP and PBMSCs combination did not improved tendon healing; (3) PRP combined with ADSCs or PRPFM with cross-linked APD improved tendon healing (Table 4).

\section{The Role of PRP in the Regeneration of Cartilage}

6.1. In Vitro Studies. PLT-derived GFs are proteins with the capacity to stimulate chondrocytes to regenerate cartilage. PRGF-treated chondrocytes showed markedly increased synthesis of proteoglycans and collagen. Plasma rich in GFs is an excellent vehicle for GFs, especially PDGF and TGF- $\beta$. In fact, several studies have documented the effectiveness of GFs in chondrogenesis and prevention of joint degeneration by controlling the synthesis and degradation of extracellular matrix proteins. Their mode of action is to bind to the extracellular domain of a target GF receptor, which in turn activates the intracellular signal transduction pathways.

Wu et al. [25] evaluate the effect of collagen matrix on the regeneration potentials of PRP for chondrocytes homeostasis showing that collagen matrix stimulated integrins and CD44 signaling was coordinated with the addition of PRP. These interactions play a critical role in regulating cell proliferation, chondrogenic and inflammatory gene expressions, and matrix remodeling of human articular chondrocytes. The study demonstrated a schematic model of collagen matrix cooperating with PRP to inhibit the ECM degradation and promote ECM synthesis and deposition. Recently, Cavallo et al. [26] assessed the effect of various PRP formulations on human chondrocytes. Results showed that PRP with a relatively low concentration of platelets and very few leukocytes stimulated chondrocyte appearing to favor some mechanisms that stimulate chondrocyte anabolism, as demonstrated by the expression of type-II collagen and aggrecan, whereas PRP with high concentrations of both platelets and leukocytes appeared to promote other biological pathways involving various cytokines. This might be due to the presence of leukocytes in PRP; the leukocytes may have been responsible for the increased expression of certain molecules such as IL-1b, IL-6, VEGF, and FGF-b, which in turn could have stimulated TIMP-1 and IL-10.

At a Glance. (1) Collagen matrix and PRP promoted cartilage ECM synthesis; (2) PRP with a relatively low concentration of PLTs and very few leukocytes stimulated chondrocyte anabolism; (3) PRP with high concentrations of both PLTs and leukocytes appeared to promote chondrocyte catabolism (Table 3).

6.2. In Vivo Studies. Some in vivo studies evaluated the effects of PRP when combined with scaffolds (polymers, collagen, and demineralized bone matrix), cells (chondrocytes and MSCs), or a combination of them.

In rabbit chondral defects, PRP incorporated in poly(lactic-co-glycolic acid) (PLGA) successfully improved the healing [114], while, in sheep and goat osteochondral defects, PRP with collagen-HA scaffolds or demineralized bone matrix did not improve or even decreased the healing $[115,116]$. Kon et al. showed not only the lack of a positive effect but also a negative influence of autologous PRP on bone and cartilage regeneration with amorphous cartilaginous repair tissue and a poorly spatially organized underlying bone tissue [115].

After the assessment of feasibility of PRP as injectable scaffold [117], an improvement in the repair of rabbit osteochondral defects after the implantation of PRP seeded with chondrocytes and a chondrocyte differentiation of BMSCs and ADSCs seeded within the PRP scaffold was observed [118]. Similarly, Lee et al. [119], using PRP gel embedded with synovial membrane derived mesenchymal stem cell (SDSCs), showed a substantial improvement in the repair of osteochondral defects in a rabbit model.

The combination of hydrogel scaffold, chondrocytes, and PRP promoted the in vivo healing of articular or nonarticular cartilage lesions, respectively, in rabbit and rat, revealing successful regeneration of hyaline chondrocytes with formation of perichondrium-like normal joint cartilage $[120,121]$. On the contrary, the separate adding of PRP or BMSCs to already available composite biphasic scaffold, composed by 
PLGA, poly(glycolic acid), and calcium sulfate, resulted in a significantly better mini. pig osteochondral defect healing, but with no synergic effects [122]. To preserve the advantages of chondrocyte therapy in a single-stage approach to osteochondral defects, Marmotti and coworkers [123] offered a single-step therapeutic approach for osteochondral defects using autologous cartilage fragments loaded onto a scaffold composed of a hyaluronic acid derivative, human fibrin glue, and PRP, in a rabbit model. Finally, the same studies $[124,125]$ using sheep and rats, evaluated the effect of PRP combined with microfractures on healing of chondral defects, showing that PRP application in addition to microfractures resulted in a better cartilage healing than microfractures alone.

At a Glance. (1) PRP incorporated in PLGA improved cartilage healing; (2) PRP with collagen-HA or demineralized bone matrix did not improve or even decreased cartilage healing; (3) good quality results in cartilage regeneration when PRP was associated with chondrocytes or MSCs with or without scaffolds (Table 4).

\section{The Role of PRP in the Regeneration of Anterior Cruciate Ligament}

7.1. In Vitro Studies. Mastrangelo et al. [27] observed that porcine and ovine ACL fibroblasts within a collagen-platelet scaffold from skeletally immature animals have greater proliferation and migration potential than adolescent and adult cells. Similar results were obtained by Magarian et al. [28] observing the response to PRP treatment in human ACL fibroblasts derived from 5 skeletally immature and 5 adolescent patients. Yoshida et al. [29] evaluated the optimal concentration of PLTs ( $1 \mathrm{x}, 3 \mathrm{x}$, and $5 \mathrm{x}$ ) to stimulate ACL healing using porcine ACL fibroblasts, revealing that $1 \mathrm{x}$ PRP was the best stimulator while higher concentrations of PLTs had diminishing effects.

At a Glance. (1) ACL fibroblasts within a collagen-platelet scaffold from skeletally immature animals had greater proliferation than adolescent and adult cells; (2) 1x PRP was the best stimulator for ACL healing in ACL fibroblasts (Table 3).

7.2. In Vivo Studies. Several authors using different animal models, porcine and canine, demonstrated that healing of transected ACL could be enhanced with the use of a collagenPRP hydrogel placed within the repair site [126-128] suggesting also that there was little functional difference in ligament healing with the use of collagen scaffolds saturated with $3 x$ or 5x PRP [129]. Differently, Zhai and coworkers [130] showed that platelet-rich gel + deproteinized bone could trigger tendon-bone healing by promoting the maturation and ossification of the tendon-bone tissue in a rabbit model. Finally, the role of PRP in promoting revascularization and reinnervation during ACL healing was clarified, using a canine animal model [131].

At a Glance. (1) Healing of transected ACL enhanced with the use of a collagen-PRP hydrogel; (2) PLTt-rich gel + deproteinized bone triggered tendon-bone healing; (3) PRP promoted revascularization and reinnervation during ACL healing (Table 4).

\section{Discussion}

Bone, cartilage, tendon, and ligament injuries have serious socioeconomic consequences in terms of health, rehabilitation, and lost working hours. The rationale of the use of PRP is that it concentrates more PLTs than the whole blood, allowing the delivery of bioactive GFs and molecules that promote tissue healing. Recently, regenerative medicine and tissue engineering focused on the use of GFs [163] and cell-based therapy to improve the quality and speed of healing suggesting that this combined biological approach may be useful even for the treatment of recalcitrant overuse musculoskeletal injuries in highly demanding patients if the appropriate dose of cells and GFs is applied [170].

No of fewer importance, PLT-rich preparations may also improve long-term outcomes in patients expected to have impaired healing, such as those with harmful lifestyle choices (e.g., smoking), medications (e.g., steroids), comorbidities (e.g., diabetes, osteoporosis, atherosclerosis, and Alzheimer), and advanced age $[171,172]$.

The use of PRP is a quick, minimally invasive, and relatively low-cost therapeutic strategy and, for these reasons, from the last three decades, PRP injections have been studied as a therapeutic alternative for different musculoskeletal injuries. The present study evaluated the last 10 years preclinical results on regenerative medicine and PRP in the musculoskeletal tissues in order to summarize the most important findings on both positive and negative data and to stimulate further preclinical and clinical research. Until 2006 PRP was preclinically investigated mainly for bone regeneration but in the last few years, the number of studies on the treatment of cartilage, ligaments, and especially tendon lesions is increasing. Even if the preclinical results did not report adverse effects, there was a wide variability among the results making it impossible to draw a standard protocol or indication for the so different musculoskeletal injuries. First and foremost, the generalized nature of the terminology may be a probable barrier to differentiate between various products and their respective protocols and it is possible that the different PRP preparation techniques, doses, and application modalities produce different results. The other main differences emerging regarded the number of centrifugations, the withdrawn blood volume, the obtained PRP final volume, the different PLT concentrations, the presence or absence of leukocytes in the final preparation, and, lastly, the use of an activator. The above listed factors are subjected to a great variability and in many papers are not specified in detail. The adoption of one of the proposed classification systems (PAW classification), in order to compare data, was not always and completely applicable, making it impossible to reach a conclusion on the best PLT concentration to be used.

The application of PRP in vitro showed promising results in all examined tissues. Researchers on bone demonstrated that the addition of PRP in cell culture medium determined good proliferation and osteogenic activity of MSCs (both BMSCs and ADSCs) and OBs. The presence of PRP had 
a positive effect in the culture of tenocytes or tendon explants and promising results were also observed with chondrocytes and ACL fibroblasts. The in vivo protocols are even more varying and complex than the in vitro ones. In bone, a wide spectrum of defects in different anatomic locations have been analyzed (calvarium, radius, tibia, condyle, iliac crest, ulna, femur, fibula, sternum, spine, frontal bone, and skull), besides vessel and bone formations in ectopic sites, employing the combination of PRP with scaffolds or autologous bone. Despite some contrasting data, in vivo studies showed encouraging results when PRP was used, also in combination with MSCs with or without other cells.

Different PRP formulations have been used for the regeneration of the most important tendons of the body: patellar, Achilles, superficial or deep digital flexor, rotator cuff, and intrasynovial flexor tendons. Similar to the bone tissue, for in vivo tendon regeneration, good results were observed when PRP was employed.

Finally, contrasting findings were observed in partial thickness, full thickness, osteochondral defects, and ACL reconstruction, although the in vivo studies on cartilage regeneration reported good quality results when PRP was associated with chondrocytes or MSC with or without scaffolds. Regarding ACL, all examined in vivo studies showed high-quality results in terms of regeneration.

To summarize, in vitro studies underlined the role of PRP for tissue regeneration and, when comparing different PRP formulations, concluded that a specific range of PLT number is required in order to obtain the best results with an increase in ECM protein expression and a decrease in the levels of proinflammatory cytokines and MMPs, via downregulation of known catabolic signaling pathways. However, the in vitro positive effects were not confirmed in all the in vivo studies because of the many variables affecting the success rate in a complex scenario where both PRP and the lesion site play a crucial role.

\section{Conclusions and Outlook for Future Research}

Despite the fact that many of the examined studies showed the potential positive effect of PRP in the treatment of musculoskeletal diseases, there is a paucity of human randomized controlled trials to provide level I evidence for the efficacy of this intervention. In fact, most of the human studies are case series or retrospective studies without a control group. Generally, they are small in size and unpowered. Thus, further evaluations are recommended and future studies should (1) find uniform and standardized nomenclature and preparation protocols; (2) optimize the number of PLTs and leukocytes cells; (3) make a direct comparison with other therapeutic techniques; (4) increase the quality of preclinical trials on safety, efficacy, and proof of concept studies; (5) clarify the role of the patient and lesion characteristics together with the local inflammatory microenvironment in the clinical outcome.

\section{Conflict of Interests}

The authors declare that they have no conflict of interests.

\section{Acknowledgments}

This work was supported by grants from Rizzoli Orthopaedic Institute (Ricerca Corrente), "Cinque per Mille 2011” funds, FIRB RBAP10MLK7 "Scaffold per la rigenerazione dei tessuti scheletrici: valutazione preclinica della loro compatibilita' ed efficienza" and by the Operational Programme ERDF 2007-2013 in the region Emilia-Romagna: Activity The 1.1 "Creation of Technology Centers for Industrial Research and Technological Transfer."

\section{References}

[1] A. D. Woolf and B. Pfleger, "Burden of major musculoskeletal conditions," Bulletin of the World Health Organization, vol. 81, no. 9, pp. 646-656, 2003.

[2] R. Bitton, "The economic burden of osteoarthritis," The American Journal of Managed Care, vol. 15, no. 8, pp. S230-S235, 2009.

[3] R. Burge, B. Dawson-Hughes, D. H. Solomon, J. B. Wong, A. King, and A. Tosteson, "Incidence and economic burden of osteoporosis-related fractures in the United States, 2005-2025," Journal of Bone and Mineral Research, vol. 22, no. 3, pp. 465-475, 2007.

[4] R. B. Frobell, L. S. Lohmander, and H. P. Roos, "Acute rotational trauma to the knee: Poor agreement between clinical assessment and magnetic resonance imaging findings," Scandinavian Journal of Medicine \& Science in Sports, vol. 17, no. 2, pp. 109-114, 2007.

[5] R. A. E. Clayton and C. M. Court-Brown, "The epidemiology of musculoskeletal tendinous and ligamentous injuries," Injury, vol. 39, no. 12, pp. 1338-1344, 2008.

[6] W. S. Pietrzak and B. L. Eppley, "Platelet rich plasma: biology and new technology," Journal of Craniofacial Surgery, vol. 16, no. 6, pp. 1043-1054, 2005.

[7] H. A. Mejia and J. P. Bradley, "The effects of platelet-rich plasma on muscle," Basic Science and Clinical Application, vol. 19, pp. 149-153, 2011.

[8] C. D. Stiles, "The molecular biology of platelet-derived growth factor," Cell, vol. 33, no. 3, pp. 653-655, 1983.

[9] C. E. Markopoulou, P. Markopoulos, X. E. Dereka, E. Pepelassi, and I. A. Vrotsos, "Effect of homologous PRP on proliferation of human periodontally affected osteoblasts. In vitro preliminary study. Report of a case," Journal of Musculoskeletal Neuronal Interactions, vol. 9, no. 3, pp. 167-172, 2009.

[10] J. Uggeri, S. Belletti, S. Guizzardi et al., "Dose-dependent effects of platelet gel releasate on activities of human osteoblasts," Journal of Periodontology, vol. 78, no. 10, pp. 1985-1991, 2007.

[11] H. H. Lu, J. M. Vo, H. S. Chin et al., "Controlled delivery of platelet-rich plasma-derived growth factors for bone formation," Journal of Biomedical Materials Research Part A, vol. 86, no. 4, pp. 1128-1136, 2008.

[12] Y. Man, P. Wang, Y. Guo et al., "Angiogenic and osteogenic potential of platelet-rich plasma and adipose-derived stem cell laden alginate microspheres," Biomaterials, vol. 33, no. 34, pp. 8802-8811, 2012.

[13] M. Kawasumi, H. Kitoh, K. A. Siwicka, and N. Ishiguro, "The effect of the platelet concentration in platelet-rich plasma gel on the regeneration of bone," The Journal of Bone and Joint Surgery-British Volume, vol. 90-B, no. 7, pp. 966-972, 2008.

[14] P. Parsons, A. Butcher, K. Hesselden et al., "Platelet-rich concentrate supports human mesenchymal stem cell proliferation, 
bone morphogenetic protein-2 messenger RNA expression, alkaline phosphatase activity, and bone formation in vitro: a mode of action to enhance bone repair," Journal of Orthopaedic Trauma, vol. 22, no. 9, pp. 595-604, 2008.

[15] T. B. Bukharova, I. V. Arutyunyan, S. A. Shustrov et al., "Tissue engineering construct on the basis of multipotent stromal adipose tissue cells and osteomatrix for regeneration of the bone tissue," Bulletin of Experimental Biology and Medicine, vol. 152, no. 1, pp. 153-158, 2011.

[16] J. Simson, J. Crist, I. Strehin, Q. Lu, and J. H. Elisseeff, “An orthopedic tissue adhesive for targeted delivery of intraoperative biologics," Journal of Orthopaedic Research, vol. 31, no. 3, pp. 392-400, 2013.

[17] F. Perut, G. Filardo, E. Mariani et al., "Preparation method and growth factor content of platelet concentrate influence the osteogenic differentiation of bone marrow stromal cells," Cytotherapy, vol. 15, no. 7, pp. 830-839, 2013.

[18] W. Zhai, N. Wang, Z. Qi, Q. Gao, and L. Yi, "Platelet-rich plasma reverses the inhibition of tenocytes and osteoblasts in tendonbone healing," Orthopedics, vol. 35, no. 4, pp. e520-e525, 2012.

[19] N. Zargar Baboldashti, R. C. Poulsen, S. L. Franklin, M. S. Thompson, and P. A. Hulley, "Platelet-rich plasma protects tenocytes from adverse side effects of dexamethasone and ciprofloxacin," The American Journal of Sports Medicine, vol. 39, no. 9, pp. 1929-1935, 2011.

[20] M. de Mos, A. E. van der Windt, H. Jahr et al., "Can plateletrich plasma enhance tendon repair? A cell culture study," The American Journal of Sports Medicine, vol. 36, no. 6, pp. 1171-1178, 2008.

[21] T. M. McCarrel, T. Minas, and L. A. Fortier, "Optimization of leukocyte concentration in platelet-rich plasma for the treatment of tendinopathy," The Journal of Bone and Joint Surgery. American Volume, vol. 94, no. 19, pp. e143.1-e143.8, 2012.

[22] C. H. Jo, J. E. Kim, K. S. Yoon, and S. Shin, "Platelet-rich plasma stimulates cell proliferation and enhances matrix gene expression and synthesis in tenocytes from human rotator cuff tendons with degenerative tears," The American Journal of Sports Medicine, vol. 40, no. 5, pp. 1035-1045, 2012.

[23] L. C. Visser, S. P. Arnoczky, O. Caballero, and M. Egerbacher, "Platelet-rich fibrin constructs elute higher concentrations of transforming growth factor- $\beta 1$ and increase tendon cell proliferation over time when compared to blood clots: a comparative in vitro analysis," Veterinary Surgery, vol. 39, no. 7, pp. 811-817, 2010.

[24] Y. Morizaki, C. Zhao, K.-N. An, and P. C. Amadio, "The effects of platelet-rich plasma on bone marrow stromal cell transplants for tendon healing in vitro," The Journal of Hand Surgery, vol. 35, no. 11, pp. 1833-1841, 2010.

[25] C.-C. Wu, W.-H. Chen, B. Zao et al., "Regenerative potentials of platelet-rich plasma enhanced by collagen in retrieving proinflammatory cytokine-inhibited chondrogenesis," Biomaterials, vol. 32, no. 25, pp. 5847-5854, 2011.

[26] C. Cavallo, G. Filardo, E. Mariani et al., "Comparison of plateletrich plasma formulations for cartilage healing: an in vitro study," The Journal of Bone and Joint Surgery-American Volume, vol. 96, no. 5, pp. 423-429, 2014.

[27] A. N. Mastrangelo, E. M. Magarian, M. P. Palmer, P. Vavken, and M. M. Murray, "The effect of skeletal maturity on the regenerative function of intrinsic ACL cells," Journal of Orthopaedic Research, vol. 28, no. 5, pp. 644-651, 2010.

[28] E. M. Magarian, P. Vavken, and M. M. Murray, "Human anterior cruciate ligament fibroblasts from immature patients have a stronger in vitro response to platelet concentrates than those from mature individuals," Knee, vol. 18, no. 4, pp. 247-251, 2011.

[29] R. Yoshida, M. Cheng, and M. M. Murray, "Increasing platelet concentration in platelet-rich plasma inhibits anterior cruciate ligament cell function in three-dimensional culture," Journal of Orthopaedic Research, vol. 32, no. 2, pp. 291-295, 2014.

[30] I. Gallo, A. Sáenz, E. Artiñano, and J. Esquide, "Autologous platelet-rich plasma: effect on sternal healing in the sheep model," Interactive Cardiovascular and Thoracic Surgery, vol. 11, no. 3, pp. 223-225, 2010.

[31] E. H. Gumieiro, M. Abrahão, R. S. Jahn et al., "Platelet-rich plasma in bone repair of irradiated tibiae of Wistar rats," Acta Cirurgica Brasileira, vol. 25, no. 3, pp. 257-263, 2010.

[32] R. Mariano, M. Messora, A. de Morais et al., "Bone healing in critical-size defects treated with platelet-rich plasma: a histologic and histometric study in the calvaria of diabetic rat," Oral Surgery, Oral Medicine, Oral Pathology, Oral Radiology and Endodontology, vol. 109, no. 1, pp. 72-78, 2010.

[33] M. R. Messora, M. J. H. Nagata, R. C. M. Dornelles et al., "Bone healing in critical-size defects treated with plateletrich plasma activated by two different methods. A histologic and histometric study in rat calvaria," Journal of Periodontal Research, vol. 43, no. 6, pp. 723-729, 2008.

[34] R. Simman, A. Hoffmann, R. J. Bohinc, W. C. Peterson, and A. J. Russ, "Role of platelet-rich plasma in acceleration of bone fracture healing," Annals of Plastic Surgery, vol. 61, no. 3, pp. 337344, 2008.

[35] Y.-H. Kang, S. H. Jeon, J.-Y. Park et al., "Platelet-rich fibrin is a bioscaffold and reservoir of growth factors for tissue regeneration," Tissue Engineering. Part A, vol. 17, no. 3-4, pp. 349-359, 2011.

[36] J. Torres, F. M. Tamimi, I. F. Tresguerres et al., "Effect of solely applied platelet-rich plasma on osseous regeneration compared to Bio-Oss: a morphometric and densitometric study on rabbit calvaria," Clinical Implant Dentistry and Related Research, vol. 10, no. 2, pp. 106-112, 2008.

[37] K. Findikcioglu, F. Findikcioglu, R. Yavuzer, C. Elmas, and K. Atabay, "Effect of platelet-rich plasma and fibrin glue on healing of critical-size calvarial bone defects," The Journal of Craniofacial Surgery, vol. 20, no. 1, pp. 34-40, 2009.

[38] L. Chen, X. Yang, G. Huang et al., "Platelet-rich plasma promotes healing of osteoporotic fractures," Orthopedics, vol. 36, no. 6, pp. e687-e694, 2013.

[39] H.-Y. Liu, A. T. H. Wu, C.-Y. Tsai et al., "The balance between adipogenesis and osteogenesis in bone regeneration by plateletrich plasma for age-related osteoporosis," Biomaterials, vol. 32, no. 28, pp. 6773-6780, 2011.

[40] M. Hakimi, P. Jungbluth, M. Sager et al., "Combined use of platelet-rich plasma and autologous bone grafts in the treatment of long bone defects in mini-pigs," Injury, vol. 41, no. 7, pp. 717723, 2010.

[41] S. R. Kanthan, G. Kavitha, S. Addi, D. S. K. Choon, and T. Kamarul, "Platelet-rich plasma (PRP) enhances bone healing in non-united critical-sized defects: a preliminary study involving rabbit models," Injury, vol. 42, no. 8, pp. 782-789, 2011.

[42] F. Molina-Miñano, P. López-Jornet, F. Camacho-Alonso, and V. Vicente-Ortega, "Plasma rich in growth factors and bone formation: a radiological and histomorphometric study in New Zealand rabbits," Brazilian Oral Research, vol. 23, no. 3, pp. 275280, 2009.

[43] M. J. H. Nagata, L. G. N. Melo, M. R. Messora et al., "Effect of platelet-rich plasma on bone healing of autogenous bone grafts 
in critical-size defects," Journal of Clinical Periodontology, vol. 36, no. 9, pp. 775-783, 2009.

[44] M. Nagata, M. Messora, R. Okamoto et al., "Influence of the proportion of particulate autogenous bone graft/platelet-rich plasma on bone healing in critical-size defects. An immunohistochemical analysis in rat calvaria," Bone, vol. 45, no. 2, pp. 339-345, 2009.

[45] M. J. H. Nagata, M. Messora, N. Pola et al., "Influence of the ratio of particulate autogenous bone graft/platelet-rich plasma on bone healing in critical-size defects: a histologic and histometric study in rat calvaria," Journal of Orthopaedic Research, vol. 28, no. 4, pp. 468-473, 2010.

[46] K. Lysiak-Drwal, M. Dominiak, L. Solski et al., "Early histological evaluation of bone defect healing with and without guided bone regeneration techniques: experimental animal studies," Postępy Higieny i Medycyny Doświadczalnej, vol. 62, pp. 282288, 2008.

[47] T.-M. You, B.-H. Choi, J. Li et al., “The effect of plateletrich plasma on bone healing around implants placed in bone defects treated with Bio-Oss: a pilot study in the dog tibia," Oral Surgery, Oral Medicine, Oral Pathology, Oral Radiology and Endodontology, vol. 103, no. 4, pp. e8-e12, 2007.

[48] M. Messora, L. Braga, G. Oliveira et al., "Healing of fresh frozen bone allograft with or without platelet-rich plasma: a histologic and histometric study in rats," Clinical Implant Dentistry and Related Research, vol. 15, no. 3, pp. 438-447, 2013.

[49] N. Broggini, W. Hofstetter, E. Hunziker et al., “The influence of PRP on early bone formation in membrane protected defects. A histological and histomorphometric study in the rabbit calvaria," Clinical Implant Dentistry and Related Research, vol. 13, no. 1, pp. 1-12, 2011.

[50] A. F. Giovanini, T. M. Deliberador, C. C. Gonzaga et al., "Platelet-rich plasma diminishes calvarial bone repair associated with alterations in collagen matrix composition and elevated CD34+ cell prevalence," Bone, vol. 46, no. 6, pp. 15971603, 2010.

[51] A. F. Giovanini, C. C. Gonzaga, J. C. Zielak et al., "Platelet-rich plasma (PRP) impairs the craniofacial bone repair associated with its elevated TGF- $\beta$ levels and modulates the co-expression between collagen III and $\alpha$-smooth muscle actin," Journal of Orthopaedic Research, vol. 29, no. 3, pp. 457-463, 2011.

[52] M. Hatakeyama, M. E. Beletti, D. Zanetta-Barbosa, and P. Dechichi, "Radiographic and histomorphometric analysis of bone healing using autogenous graft associated with plateletrich plasma obtained by 2 different methods," Oral Surgery, Oral Medicine, Oral Pathology, Oral Radiology and Endodontology, vol. 105, no. 1, pp. e13-e18, 2008.

[53] M. A. de Oliveira Filho, P. A. N. Nassif, O. Malafaia et al., "Effects of a highly concentrated platelet-rich plasma on the bone repair using non-critical defects in the calvaria of rabbits," Acta Cirurgica Brasileira, vol. 25, no. 1, pp. 28-33, 2010.

[54] S. R. Miranda, H. N. Filho, L. E. Marques Padovan, D. A. Ribeiro, D. Nicolielo, and M. A. Matsumoto, "Use of plateletrich plasma under autogenous onlay bone grafts," Clinical Oral Implants Research, vol. 17, no. 6, pp. 694-699, 2006.

[55] R. E. C. M. Mooren, M. A. W. Merkx, E. M. Bronkhorst, J. A. Jansen, and P. J. W. Stoelinga, "The effect of platelet-rich plasma on early and late bone healing: an experimental study in goats," International Journal of Oral and Maxillofacial Surgery, vol. 36, no. 7, pp. 626-631, 2007.

[56] R. E. C. M. Mooren, A. C. A. Dankers, M. A. W. Merkx, E. M. Bronkhorst, J. A. Jansen, and P. J. W. Stoelinga, "The effect of platelet-rich plasma on early and late bone healing using a mixture of particulate autogenous cancellous bone and Bio-Oss: an experimental study in goats," International Journal of Oral \& Maxillofacial Surgery, vol. 39, no. 4, pp. 371-378, 2010.

[57] I. Guerra, F. Morais Branco, M. Vasconcelos, A. Afonso, H. Figueiral, and R. Zita, "Evaluation of implant osseointegration with different regeneration techniques in the treatment of bone defects around implants: an experimental study in a rabbit model," Clinical Oral Implants Research, vol. 22, no. 3, pp. 314322, 2011.

[58] A. Oryan, A. Meimandi Parizi, Z. Shafiei-Sarvestani, and A. S. Bigham, "Effects of combined hydroxyapatite and human platelet rich plasma on bone healing in rabbit model: radiological, macroscopical, hidtopathological and biomechanical evaluation," Cell and Tissue Banking, vol. 13, no. 4, pp. 639-651, 2012.

[59] P. Metzler, C. von Wilmowsky, R. Zimmermann, J. Wiltfang, and K. A. Schlegel, "The effect of current used bone substitution materials and platelet-rich plasma on periosteal cells by ectopic site implantation: an in-vivo pilot study," Journal of CranioMaxillofacial Surgery, vol. 40, no. 5, pp. 409-415, 2012.

[60] J.-C. Chen, C.-L. Ko, C.-J. Shih, Y.-C. Tien, and W.-C. Chen, "Calcium phosphate bone cement with $10 \mathrm{wt} \%$ platelet-rich plasma in vitro and in vivo," Journal of Dentistry, vol. 40, no. 2, pp. 114-122, 2012.

[61] P. Jungbluth, M. Wild, J.-P. Grassmann et al., "Platelet-rich plasma on calcium phosphate granules promotes metaphyseal bone healing in mini-pigs," Journal of Orthopaedic Research, vol. 28, no. 11, pp. 1448-1455, 2010.

[62] A. S. Plachokova, J. van den Dolder, P. J. Stoelinga, and J. A. Jansen, "Early effect of platelet-rich plasma on bone healing in combination with an osteoconductive material in rat cranial defects," Clinical Oral Implants Research, vol. 18, no. 2, pp. 244251, 2007.

[63] Y.-D. Zhang, G. Wang, Y. Sun, and C.-Q. Zhang, "Combination of platelet-rich plasma with degradable bioactive borate glass for segmental bone defect repair," Acta Orthopaedica Belgica, vol. 77, no. 1, pp. 110-115, 2011.

[64] K. Yoshida, Y. Sumita, E. Marukawa, M. Harashima, and I. Asahina, "Effect of platelet-rich plasma on bone engineering with an alloplastic substitute containing BMP2," Bio-Medical Materials and Engineering, vol. 23, no. 3, pp. 163-172, 2013.

[65] S.-H. Chang, Y.-M. Hsu, Y. J. Wang, Y.-P. Tsao, K.-Y. Tung, and T.-Y. Wang, "Fabrication of pre-determined shape of bone segment with collagen-hydroxyapatite scaffold and autogenous platelet-rich plasma," Journal of Materials Science: Materials in Medicine, vol. 20, no. 1, pp. 23-31, 2009.

[66] H. C. Kroese-Deutman, J. W. M. Vehof, P. H. M. Spauwen, P. J. W. Stoelinga, and J. A. Jansen, "Orthotopic bone formation in titanium fiber mesh loaded with platelet-rich plasma and placed in segmental defects," International Journal of Oral and Maxillofacial Surgery, vol. 37, no. 6, pp. 542-549, 2008.

[67] E.-J. Park, E.-S. Kim, H.-P. Weber, R. F. Wright, and D. J. Mooney, "Improved bone healing by angiogenic factorenriched platelet-rich plasma and its synergistic enhancement by bone morphogenetic protein-2," The International Journal of Oral and Maxillofacial Implants, vol. 23, no. 5, pp. 818-826, 2008.

[68] B. Rai, M. E. Oest, K. M. Dupont, K. H. Ho, S. H. Teoh, and R. E. Guldberg, "Combination of platelet-rich plasma with polycaprolactone-tricalcium phosphate scaffolds for segmental bone defect repair," Journal of Biomedical Materials Research Part A, vol. 81, no. 4, pp. 888-899, 2007. 
[69] Y.-H. Kim, H. Furuya, and Y. Tabata, "Enhancement of bone regeneration by dual release of a macrophage recruitment agent and platelet-rich plasma from gelatin hydrogels," Biomaterials, vol. 35, no. 1, pp. 214-224, 2014.

[70] A. Hokugo, Y. Sawada, R. Hokugo et al., "Controlled release of platelet growth factors enhances bone regeneration at rabbit calvaria," Oral Surgery, Oral Medicine, Oral Pathology, Oral Radiology and Endodontology, vol. 104, no. 1, pp. 44-48, 2007.

[71] N. Tsuzuki, J.-P. Seo, K. Yamada, S. Haneda, Y. Tabata, and N. Sasaki, "Effect of compound of gelatin hydrogel microsphere incorporated with platelet-rich-plasma and alginate on sole defect in cattle," The Journal of Veterinary Medical Science, vol. 74, no. 8, pp. 1041-1044, 2012.

[72] A. Meimandi Parizi, A. Oryan, Z. Shafiei-Sarvestani, and A. S. Bigham, "Human platelet rich plasma plus Persian Gulf coral effects on experimental bone healing in rabbit model: radiological, histological, macroscopical and biomechanical evaluation," Journal of Materials Science: Materials in Medicine, vol. 23, no. 2, pp. 473-483, 2012.

[73] Z. Shafiei-Sarvestani, A. Oryan, A. S. Bigham, and A. Meimandi-Parizi, "The effect of hydroxyapatite-hPRP, and coral-hPRP on bone healing in rabbits: radiological, biomechanical, macroscopic and histopathologic evaluation," International Journal of Surgery, vol. 10, no. 2, pp. 96-101, 2012.

[74] E. O. Oktay, B. Demiralp, S. Senel, A. Cevdet Akman, K. Eratalay, and H. Akincibay, "Effects of platelet-rich plasma and chitosan combination on bone regeneration in experimental rabbit cranial defects," The Journal of Oral Implantology, vol. 36, no. 3, pp. 175-184, 2010.

[75] C. F. N. Paulo, S. D. C. V. Abib, R. F. Neves et al., "Effect of hyperbaric oxygen therapy combined with autologous platelet concentrate applied in rabbit fibula fraction healing," Clinics, vol. 68, no. 9, pp. 1239-1246, 2013.

[76] Y.-C. Por, C. R. Barceló, K. E. Salyer et al., "Bone generation in the reconstruction of a critical size calvarial defect in an experimental model," Journal of Craniofacial Surgery, vol. 19, no. 2, pp. 383-392, 2008.

[77] A. S. Plachokova, J. van den Dolder, J. J. J. P. van den Beucken, and J. A. Jansen, "Bone regenerative properties of rat, goat and human platelet-rich plasma," International Journal of Oral and Maxillofacial Surgery, vol. 38, no. 8, pp. 861-869, 2009.

[78] B. Özdemir, B. Kurtiş, G. Tüter et al., "Double-application of platelet-rich plasma on bone healing in rabbits," Medicina Oral, Patologia Oral y Cirugia Bucal, vol. 17, no. 1, pp. e171-e177, 2012.

[79] G. Cinotti, A. Corsi, B. Sacchetti, M. Riminucci, P. Bianco, and G. Giannicola, "Bone ingrowth and vascular supply in experimental spinal fusion with platelet-rich plasma," Spine, vol. 38, no. 5, pp. 385-391, 2013.

[80] W. P. Clafshenkel, J. L. Rutkowski, R. N. Palchesko et al., "A novel calcium aluminate-melatonin scaffold enhances bone regeneration within a calvarial defect," Journal of Pineal Research, vol. 53, no. 2, pp. 206-218, 2012.

[81] K. A. Schlegel, M. Thorwarth, A. Plesinac, J. Wiltfang, and S. Rupprecht, "Expression of bone matrix proteins during the osseus healing of topical conditioned implants: an experimental study," Clinical Oral Implants Research, vol. 17, no. 6, pp. 666672, 2006.

[82] D. Nikolidakis, J. van den Dolder, J. G. C. Wolke, and J. A. Jansen, "Effect of platelet-rich plasma on the early bone formation around Ca-P-coated and non-coated oral implants in cortical bone," Clinical Oral Implants Research, vol. 19, no. 2, pp. 207-213, 2008.
[83] X. Cheng, D. Lei, T. Mao, S. Yang, F. Chen, and W. Wu, "Repair of critical bone defects with injectable platelet rich plasma/bone marrow-derived stromal cells composite: experimental study in rabbits," Ulusal Travma ve Acil Cerrahi Dergisi, vol. 14, no. 2, pp. 87-95, 2008.

[84] Z.-Q. Jiang, H.-Y. Liu, L.-P. Zhang, Z.-Q. Wu, and D.-Z. Shang, "Repair of calvarial defects in rabbits with platelet-rich plasma as the scaffold for carrying bone marrow stromal cells," Oral Surgery, Oral Medicine, Oral Pathology and Oral Radiology, vol. 113, no. 3, pp. 327-333, 2012.

[85] B. S. Monteiro, R. J. del Carlo, N. M. Argôlo-Neto et al., "Association of mesenchymal stem cells with platelet rich plasma on the repair of critical calvarial defects in mice," Acta Cirurgica Brasileira, vol. 27, no. 3, pp. 201-209, 2012.

[86] P. Niemeyer, K. Fechner, S. Milz et al., "Comparison of mesenchymal stem cells from bone marrow and adipose tissue for bone regeneration in a critical size defect of the sheep tibia and the influence of platelet-rich plasma," Biomaterials, vol. 31, no. 13, pp. 3572-3579, 2010.

[87] Y. Liu, Y. Zhou, H. Feng, G.-E. Ma, and Y. Ni, "Injectable tissueengineered bone composed of human adipose-derived stromal cells and platelet-rich plasma," Biomaterials, vol. 29, no. 23, pp. 3338-3345, 2008.

[88] S. Agacayak, B. Gulsun, M. C. Ucan, E. Karaoz, and Y. Nergiz, "Effects of mesenchymal stem cells in critical size bone defect," European Review for Medical and Pharmacological Sciences, vol. 16, no. 5, pp. 679-686, 2012.

[89] P. Kasten, M. Beverungen, H. Lorenz, J. Wieland, M. Fehr, and F. Geiger, "Comparison of platelet-rich plasma and VEGFtransfected mesenchymal stem cells on vascularization and bone formation in a critical-size bone defect," Cells Tissues Organs, vol. 196, no. 6, pp. 523-533, 2012.

[90] P. Kasten, J. Vogel, F. Geiger, P. Niemeyer, R. Luginbühl, and K. Szalay, "The effect of platelet-rich plasma on healing in criticalsize long-bone defects," Biomaterials, vol. 29, no. 29, pp. 39833992, 2008.

[91] R. M. El Backly, S. H. Zaky, A. Muraglia et al., "A plateletrich plasma-based membrane as a periosteal substitute with enhanced osteogenic and angiogenic properties: a new concept for bone repair," Tissue Engineering, Part A, vol. 19, no. 1-2, pp. 152-165, 2013.

[92] M. A. Batista, T. P. Leivas, C. J. Rodrigues, G. C. F. Arenas, D. R. Belitardo, and R. Guarniero, "Comparison between the effects of platelet-rich plasma and bone marrow concentrate on defect consolidation in the rabbit tibia," Clinics, vol. 66, no. 10, pp. 1787-1792, 2011.

[93] W. Zhong, Y. Sumita, S. Ohba et al., "In vivo comparison of the bone regeneration capability of human bone marrow concentrates vs. platelet-rich plasma," PLoS ONE, vol. 7, no. 7, Article ID e40833, 2012.

[94] H. Behnia, A. Khojasteh, M. T. Kiani et al., "Bone regeneration with a combination of nanocrystalline hydroxyapatite silica gel, platelet-rich growth factor, and mesenchymal stem cells: a histologic study in rabbit calvaria," Oral Surgery, Oral Medicine, Oral Pathology and Oral Radiology, vol. 115, no. 2, pp. 7-15, 2013.

[95] Z.-Y. Zhang, A.-W. Huang, J. J. Fan et al., “The potential use of allogeneic platelet-rich plasma for large bone defect treatment: immunogenicity and defect healing efficacy," Cell Transplantation, vol. 22, no. 1, pp. 175-187, 2013.

[96] D. N. Lyras, K. Kazakos, G. Agrogiannis et al., "Experimental study of tendon healing early phase: is IGF-1 expression influenced by platelet rich plasma gel?" Orthopaedics and 
Traumatology: Surgery and Research, vol. 96, no. 4, pp. 381-387, 2010.

[97] D. N. Lyras, K. Kazakos, M. Tryfonidis et al., "Temporal and spatial expression of TGF-betal in an Achilles tendon section model after application of platelet-rich plasma," Foot and Ankle Surgery, vol. 16, no. 3, pp. 137-141, 2010.

[98] D. Lyras, K. Kazakos, D. Verettas et al., "Immunohistochemical study of angiogenesis after local administration of platelet-rich plasma in a patellar tendon defect," International Orthopaedics, vol. 34, no. 1, pp. 143-148, 2010.

[99] G. Bosch, P. René van Weeren, A. Barneveld, and H. T. M. van Schie, "Computerised analysis of standardised ultrasonographic images to monitor the repair of surgically created core lesions in equine superficial digital flexor tendons following treatment with intratendinous platelet rich plasma or placebo," The Veterinary Journal, vol. 187, no. 1, pp. 92-98, 2011.

[100] G. Bosch, H. T. M. van Schie, M. W. de Groot et al., "Effects of platelet-rich plasma on the quality of repair of mechanically induced core lesions in equine superficial digital flexor tendons: a placebo-controlled experimental study," Journal of Orthopaedic Research, vol. 28, no. 2, pp. 211-217, 2010.

[101] Y. Kajikawa, T. Morihara, H. Sakamoto et al., "Platelet-rich plasma enhances the initial mobilization of circulation-derived cells for tendon healing," Journal of Cellular Physiology, vol. 215, no. 3, pp. 837-845, 2008.

[102] O. Hapa, H. Çakici, A. Kükner, H. Aygün, N. Sarkalkan, and G. Baysal, "Effect of platelet-rich plasma on tendon-to-bone healing after rotator cuff repair in rats: an in vivo experimental study," Acta Orthopaedica et Traumatologica Turcica, vol. 46, no. 4, pp. 301-307, 2012.

[103] J.-F. Kaux, P. V. Drion, A. Colige et al., "Effects of platelet-rich plasma (PRP) on the healing of Achilles tendons of rats," Wound Repair and Regeneration, vol. 20, no. 5, pp. 748-756, 2012.

[104] J. Beck, D. Evans, P. M. Tonino, S. Yong, and J. J. Callaci, "The biomechanical and histologic effects of platelet-rich plasma on rat rotator cuff repairs," The American Journal of Sports Medicine, vol. 40, no. 9, pp. 2037-2044, 2012.

[105] D. N. Lyras, K. Kazakos, G. Georgiadis et al., "Does a single application of PRP alter the expression of IGF-I in the early phase of tendon healing?" Journal of Foot and Ankle Surgery, vol. 50, no. 3, pp. 276-282, 2011.

[106] J. A. Fernández-Sarmiento, J. M. Domínguez, M. M. Granados et al., "Histological study of the influence of plasma rich in growth factors (PRGF) on the healing of divided Achilles tendons in sheep," The Journal of Bone \& Joint SurgeryAmerican Volume, vol. 95, no. 3, pp. 246-255, 2013.

[107] D. Sato, M. Takahara, A. Narita et al., "Effect of platelet-rich plasma with fibrin matrix on healing of intrasynovial flexor tendons," Journal of Hand Surgery, vol. 37, no. 7, pp. 1356-1363, 2012.

[108] J. T. Spang, T. Tischer, G. M. Salzmann et al., "Platelet concentrate vs. saline in a rat patellar tendon healing model," Knee Surgery, Sports Traumatology, Arthroscopy, vol. 19, no. 3, pp. 495-502, 2011.

[109] T. Martinello, I. Bronzini, A. Perazzi et al., "Effects of in vivo applications of peripheral blood-derived mesenchymal stromal cells (PB-MSCs) and platlet-rich plasma (PRP) on experimentally injured deep digital flexor tendons of sheep," Journal of Orthopaedic Research, vol. 31, no. 2, pp. 306-314, 2013.

[110] C. A. Uysal, M. Tobita, H. Hyakusoku, and H. Mizuno, "Adipose-derived stem cells enhance primary tendon repair: biomechanical and immunohistochemical evaluation," Journal of Plastic, Reconstructive \& Aesthetic Surgery, vol. 65, no. 12, pp. 1712-1719, 2012.

[111] T. L. Sarrafian, H. Wang, E. S. Hackett et al., "Comparison of Achilles tendon repair techniques in a sheep model using a cross-linked acellular porcine dermal patch and platelet-rich plasma fibrin matrix for augmentation," Journal of Foot and Ankle Surgery, vol. 49, no. 2, pp. 128-134, 2010.

[112] L. Chen, S.-W. Dong, J.-P. Liu, X. Tao, K.-L. Tang, and J.-Z. $\mathrm{Xu}$, "Synergy of tendon stem cells and platelet-rich plasma in tendon healing," Journal of Orthopaedic Research, vol. 30, no. 6, pp. 991-997, 2012.

[113] X. Wang, Y. Qiu, J. Triffitt, A. Carr, Z. Xia, and A. Sabokbar, "Proliferation and differentiation of human tenocytes in response to platelet rich plasma: an in vitro and in vivo study," Journal of Orthopaedic Research, vol. 30, no. 6, pp. 982-990, 2012.

[114] Y. Sun, Y. Feng, C. Q. Zhang, S. B. Chen, and X. G. Cheng, "The regenerative effect of platelet-rich plasma on healing in large osteochondral defects," International Orthopaedics, vol. 34, no. 4, pp. 589-597, 2010.

[115] E. Kon, G. Filardo, M. Delcogliano et al., "Platelet autologous growth factors decrease the osteochondral regeneration capability of a collagen-hydroxyapatite scaffold in a sheep model," BMC Musculoskeletal Disorders, vol. 11, article 220, 2010.

[116] C. J. A. van Bergen, G. M. M. J. Kerkhoffs, M. Özdemir et al., "Demineralized bone matrix and platelet-rich plasma do not improve healing of osteochondral defects of the talus: an experimental goat study," Osteoarthritis and Cartilage, vol. 21, no. 11, pp. 1746-1754, 2013.

[117] W. Wu, F. Chen, Y. Liu, Q. Ma, and T. Mao, "Autologous injectable tissue-engineered cartilage by using platelet-rich plasma: experimental study in a rabbit model," Journal of Oral and Maxillofacial Surgery, vol. 65, no. 10, pp. 1951-1957, 2007.

[118] X. Xie, Y. Wang, C. Zhao et al., "Comparative evaluation of MSCs from bone marrow and adipose tissue seeded in PRPderived scaffold for cartilage regeneration," Biomaterials, vol. 33, no. 29, pp. 7008-7018, 2012.

[119] J.-C. Lee, H. J. Min, H. J. Park, S. Lee, S. C. Seong, and M. C. Lee, "Synovial membrane-derived mesenchymal stem cells supported by platelet-rich plasma can repair osteochondral defects in a rabbit model," Arthroscopy, vol. 29, no. 6, pp. 10341046, 2013.

[120] H.-R. Lee, K. M. Park, Y. K. Joung, K. D. Park, and S. H. Do, "Platelet-rich plasma loaded in situ-formed hydrogel enhances hyaline cartilage regeneration by CB1 upregulation," Journal of Biomedical Materials Research-Part A, vol. 100, no. 11, pp. 3099-3107, 2012.

[121] H.-R. Lee, K. M. Park, Y. K. Joung, K. D. Park, and S. H. Do, "Platelet-rich plasma loaded hydrogel scaffold enhances chondrogenic differentiation and maturation with up-regulation of CB1 and CB2," Journal of Controlled Release, vol. 159, no. 3, pp. 332-337, 2012.

[122] M. Betsch, J. Schneppendahl, S. Thuns et al., "Bone marrow aspiration concentrate and platelet rich plasma for osteochondral repair in a porcine osteochondral defect model," PLOS ONE, vol. 8, no. 8, Article ID e71602, 2013.

[123] A. Marmotti, M. Bruzzone, D. E. Bonasia et al., "One-step osteochondral repair with cartilage fragments in a composite scaffold," Knee Surgery, Sports Traumatology, Arthroscopy, vol. 20, no. 12, pp. 2590-2601, 2012. 
[124] G. Milano, E. S. Passino, L. Deriu et al., "The effect of platelet rich plasma combined with microfractures on the treatment of chondral defects: an experimental study in a sheep model," Osteoarthritis and Cartilage, vol. 18, no. 7, pp. 971-980, 2010.

[125] O. Hapa, H. Çakici, H. Y. Yüksel, T. Firat, A. Kükner, and H. Aygün, "Does platelet-rich plasma enhance microfracture treatment for chronic focal chondral defects? An in-vivo study performed in a rat model," Acta Orthopaedica et Traumatologica Turcica, vol. 47, no. 3, pp. 201-207, 2013.

[126] M. M. Murray, K. P. Spindler, E. Abreu et al., "Collagen-platelet rich plasma hydrogel enhances primary repair of the porcine anterior cruciate ligament," Journal of Orthopaedic Research, vol. 25, no. 1, pp. 81-91, 2007.

[127] M. M. Murray, K. P. Spindler, P. Ballard, T. P. Welch, D. Zurakowski, and L. B. Nanney, "Enhanced histologic repair in a central wound in the anterior cruciate ligament with a collagenplatelet-rich plasma scaffold," Journal of Orthopaedic Research, vol. 25, no. 8, pp. 1007-1017, 2007.

[128] M. M. Murray, M. Palmer, E. Abreu, K. P. Spindler, D. Zurakowski, and B. C. Fleming, "Platelet-rich plasma alone is not sufficient to enhance suture repair of the ACL in skeletally immature animals: an in vivo study," Journal of Orthopaedic Research, vol. 27, no. 5, pp. 639-645, 2009.

[129] A. N. Mastrangelo, P. Vavken, B. C. Fleming, S. L. Harrison, and M. M. Murray, "Reduced platelet concentration does not harm PRP effectiveness for ACL repair in a porcine in vivo model," Journal of Orthopaedic Research, vol. 29, no. 7, pp. 1002-1007, 2011.

[130] W. Zhai, C. Lv, Y. Zheng, Y. Gao, Z. Ding, and Z. Chen, "Weak link of tendon-bone healing and a control experiment to promote healing," Archives of Orthopaedic and Trauma Surgery, vol. 133, no. 11, pp. 1533-1541, 2013.

[131] X. Xie, S. Zhao, H. Wu et al., "Platelet-rich plasma enhances autograft revascularization and reinnervation in a dog model of anterior cruciate ligament reconstruction," Journal of Surgical Research, vol. 183, no. 1, pp. 214-222, 2013.

[132] B. di Matteo, G. Filardo, M. Lo Presti, E. Kon, and M. Marcacci, "Chronic anti-platelet therapy: a contraindication for plateletrich plasma intra-articular injections?" European Review for Medical \& Pharmacological Sciences, vol. 18, no. 1, supplement, pp. 55-59, 2014.

[133] F. Vannini, B. Di Matteo, G. Filardo, E. Kon, M. Marcacci, and S. Giannini, "Platelet-rich plasma for foot and ankle pathologies: a systematic review," Foot and Ankle Surgery, vol. 20, no. 1, pp. 2-9, 2014.

[134] G. Filardo, E. Kon, A. Roffi, B. Di Matteo, M. L. Merli, and M. Marcacci, "Platelet-rich plasma: why intra-articular? A systematic review of preclinical studies and clinical evidence on PRP for joint degeneration," Knee Surgery, Sports Traumatology, Arthroscopy, 2013.

[135] G. Filardo, E. Kon, B. Di Matteo, P. Pelotti, A. Di Martino, and M. Marcacci, "Platelet-rich plasma for the treatment of patellar tendinopathy: clinical and imaging findings at medium-term follow-up," International Orthopaedics, vol. 37, no. 8, pp. 15831589, 2013.

[136] F. A. Barber, S. A. Hrnack, S. J. Snyder, and O. Hapa, "Rotator cuff repair healing influenced by platelet-rich plasma construct augmentation," Arthroscopy, vol. 27, no. 8, pp. 1029-1035, 2011.

[137] M. Vogrin, M. Rupreht, D. Dinevski et al., "Effects of a platelet gel on early graft revascularization after anterior cruciate ligament reconstruction: a prospective, randomized, doubleblind, clinical trial," European Surgical Research, vol. 45, no. 2, pp. 77-85, 2010.

[138] M. S. A. Hamid, A. Yusof, and M. R. Mohamed Ali, "Plateletrich plasma (PRP) for acute muscle injury: a systematic review," PLoS ONE, vol. 9, no. 2, Article ID e90538, 2014.

[139] I. Andia and N. Maffulli, "Platelet-rich plasma for muscle injury and tendinopathy," Sports Medicine and Arthroscopy Review, vol. 21, no. 4, pp. 191-198, 2013.

[140] J.-F. Kaux, C. Le Goff, L. Seidel et al., "Comparative study of five techniques of preparation of platelet-rich plasma," Pathologie Biologie, vol. 59, no. 3, pp. 157-160, 2011.

[141] T. N. Castillo, M. A. Pouliot, and J. L. Dragoo, "Comparison of growth factor and platelet concentration from commercial platelet-rich plasma separation systems," The American Journal of Sports Medicine, vol. 39, no. 2, pp. 266-271, 2011.

[142] E. Anitua, M. Sánchez, G. Orive, and I. Andía, “The potential impact of the preparation rich in growth factors (PRGF) in different medical fields," Biomaterials, vol. 28, no. 31, pp. 45514560, 2007.

[143] K. Werther, I. J. Christensen, and H. J. Nielsen, "Determination of vascular endothelial growth factor (VEGF) in circulating blood: significance of VEGF in various leucocytes and platelets," Scandinavian Journal of Clinical and Laboratory Investigation, vol. 62, no. 5, pp. 343-350, 2002.

[144] E. Anitua, I. Andia, B. Ardanza, P. Nurden, and A. T. Nurden, "Autologous platelets as a source of proteins for healing and tissue regeneration," Thrombosis and Haemostasis, vol. 91, no. 1, pp. 4-15, 2004.

[145] J.-F. Kaux, L. Janssen, P. Drion et al., "Vascular endothelial growth factor-111 (VEGF-111) and tendon healing: preliminary results in a rat model of tendon injury," Muscles, Ligaments and Tendons Journal, vol. 4, no. 1, pp. 24-28, 2014.

[146] J. F. Kaux, J. L. Croisier, O. Bruyere et al., "One injection of platelet-rich plasma associated to a submaximal eccentric protocol to treat chronic jumper's knee," The Journal of Sports Medicine and Physical Fitness. In press.

[147] J. R. Evanson, M. K. Guyton, D. L. Oliver et al., "Gender and age differences in growth factor concentrations from platelet-rich plasma in adults," Military Medicine, vol. 179, no. 7, pp. 799-805, 2014.

[148] M. Tschon, M. Fini, R. Giardino et al., "Lights and shadows concerning platelet products for musculoskeletal regeneration," Frontiers in Bioscience -Elite, vol. 3, no. 1, pp. 96-107, 2011.

[149] J. M. Delong, R. P. Russell, and A. D. Mazzocca, "Plateletrich plasma: the PAW classification system," The Journal of Arthroscopic and Related Surgery, vol. 28, no. 7, pp. 998-1009, 2012.

[150] D. M. Dohan Ehrenfest, I. Andia, M. A. Zumstein, C.-Q. Zhang, N. R. Pinto, and T. Bielecki, "Classification of platelet concentrates (Platelet-Rich Plasma-PRP, Platelet-Rich Fibrin$\mathrm{PRF}$ ) for topical and infiltrative use in orthopedic and sports medicine: current consensus, clinical implications and perspectives," Muscles, Ligaments and Tendons Journal, vol. 4, no. 1, pp. 3-9, 2014.

[151] A. P. M. H. Wroblewski, H. A. Mejia, and V. J. Wright, "Application of platelet-rich plasma to enhance tissue repair," Operative Techniques in Orthopaedics, vol. 20, no. 2, pp. 98-105, 2010.

[152] A. T. Nurden, P. Nurden, M. Sanchez, I. Andia, and E. Anitua, "Platelets and wound healing," Frontiers in Bioscience, vol. 13, no. 9, pp. 3532-3548, 2008. 
[153] A. T. Nurden, "Platelets, inflammation and tissue regeneration," Thrombosis and Haemostasis, vol. 105, supplement 1, pp. 13-33, 2011.

[154] R. E. Marx, "Platelet-rich plasma (PRP): what is PRP and what is not PRP?" Implant Dentistry, vol. 10, no. 4, pp. 225-228, 2001.

[155] B. C. Halpern, S. Chaudhury, and S. A. Rodeo, "The role of platelet-rich plasma in inducing musculoskeletal tissue healing," HSS Journal, vol. 8, no. 2, pp. 137-145, 2012.

[156] T. E. Foster, B. L. Puskas, B. R. Mandelbaum, M. B. Gerhardt, and S. A. Rodeo, "Platelet-rich plasma: from basic science to clinical applications," The American Journal of Sports Medicine, vol. 37, no. 11, pp. 2259-2272, 2009.

[157] H. El-Sharkawy, A. Kantarci, J. Deady et al., "Platelet-rich plasma: growth factors and pro- and anti-inflammatory properties," Journal of Periodontology, vol. 78, no. 4, pp. 661-669, 2007.

[158] F. L. Gimeno, S. Gatto, J. Ferro, J. O. Croxatto, and J. E. Gallo, "Preparation of platelet-rich plasma as a tissue adhesive for experimental transplantation in rabbits," Thrombosis Journal, vol. 4 , article 18, 2006.

[159] B. Han, J. Woodell-May, M. Ponticiello, Z. Yang, and M. Nimni, "The effect of thrombin activation of platelet-rich plasma on demineralized bone matrix osteoinductivity," The Journal of Bone and Joint Surgery-American Volume, vol. 91, no. 6, pp. 1459-1470, 2009.

[160] B. M. Mitruka and H. M. Rawnsley, Clinical Biochemical and Hematological Reference Values in Normal Experimental Animals, Masson, 1977.

[161] P. A. M. Everts, J. Hoffmann, G. Weibrich et al., "Differences in platelet growth factor release and leucocyte kinetics during autologous platelet gel formation," Transfusion Medicine, vol. 16, no. 5, pp. 363-368, 2006.

[162] G. Bettega and E. Schir, "Contribution of platelet concentrates to oral and maxillo-facial surgery," Revue de Stomatologie et de Chirurgie Maxillo-Faciale, vol. 113, no. 4, pp. 205-211, 2012.

[163] E. Anitua, M. Sánchez, and G. Orive, "The importance of understanding what is platelet-rich growth factor (PRGF) and what is not," Journal of Shoulder and Elbow Surgery, vol. 20, no. 1, pp. e23-e24, 2011.

[164] V. Y. Moraes, M. Lenza, M. J. Tamaoki, F. Faloppa, and J. C. Belloti, "Platelet-rich therapies for musculoskeletal soft tissue injuries," The Cochrane Database of Systematic Reviews, vol. 12, Article ID CD010071, 2013.

[165] A. Wang-Saegusa, R. Cugat, O. Ares, R. Seijas, X. Cuscó, and M. Garcia-Balletbó, "Infiltration of plasma rich in growth factors for osteoarthritis of the knee short-term effects on function and quality of life," Archives of Orthopaedic and Trauma Surgery, vol. 131, no. 3, pp. 311-317, 2011.

[166] S. Sampson, M. Gerhardt, and B. Mandelbaum, "Platelet rich plasma injection grafts for musculoskeletal injuries: a review," Ethics in Science and Environmental Politics, vol. 1, no. 3-4, pp. 165-174, 2008.

[167] J. L. Zehnder and L. L. K. Leung, "Development of antibodies to thrombin and factor $\mathrm{V}$ with recurrent bleeding in a patient exposed to topical bovine thrombin," Blood, vol. 76, no. 10, pp. 2011-2016, 1990.

[168] R. S. Dhillon, E. M. Schwarz, and M. D. Maloney, "Plateletrich plasma therapy-future or trend?" Arthritis Research and Therapy, vol. 14, no. 4, article 219, 2012.

[169] A. Khojasteh, M. B. Eslaminejad, and H. Nazarian, "Mesenchymal stem cells enhance bone regeneration in rat calvarial critical size defects more than platelete-rich plasma," Oral Surgery, Oral
Medicine, Oral Pathology, Oral Radiology and Endodontology, vol. 106, no. 3, pp. 356-362, 2008.

[170] P. Torricelli, M. Fini, G. Filardo et al., "Regenerative medicine for the treatment of musculoskeletal overuse injuries in competition horses," International Orthopaedics, vol. 35, no. 10, pp. 1569-1576, 2011.

[171] E. Anitua, C. Pascual, D. Antequera et al., "Plasma rich in growth factors (PRGF-Endoret) reduces neuropathologic hallmarks and improves cognitive functions in an Alzheimer's disease mouse model," Neurobiology of Aging, vol. 35, no. 7, pp. 1582-1595, 2014.

[172] V. L. Davis, A. B. Abukabda, N. M. Radio et al., "Platelet-rich preparations to improve healing. Part I: workable options for every size practice," Journal of Oral Implantology, vol. 40, no. 4, pp. 500-510, 2014. 


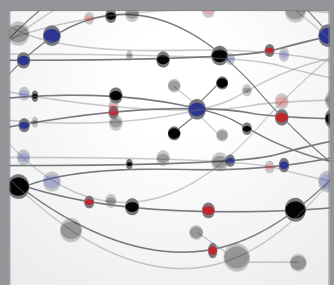

The Scientific World Journal
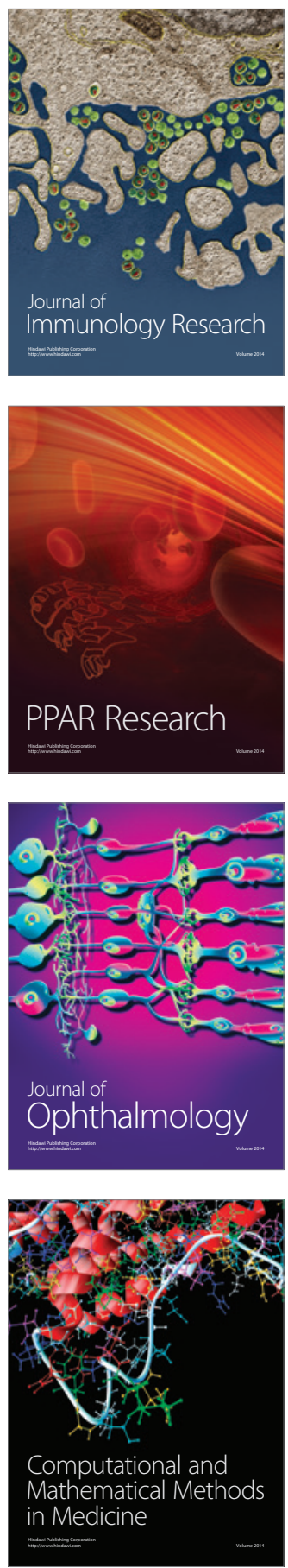

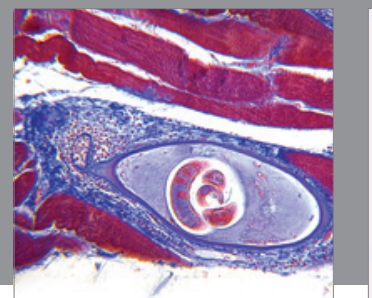

Gastroenterology

Research and Practice
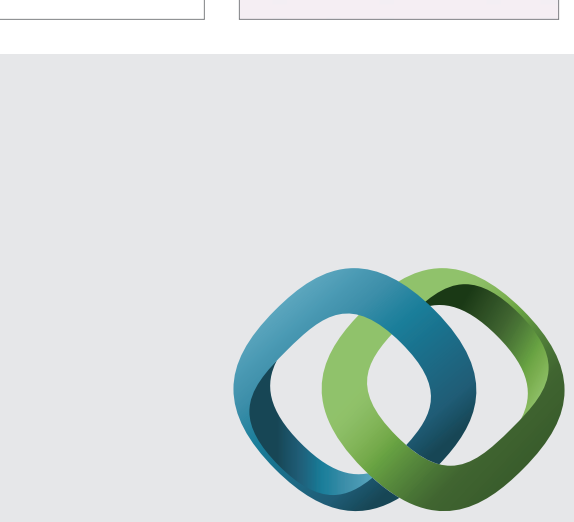

\section{Hindawi}

Submit your manuscripts at

http://www.hindawi.com
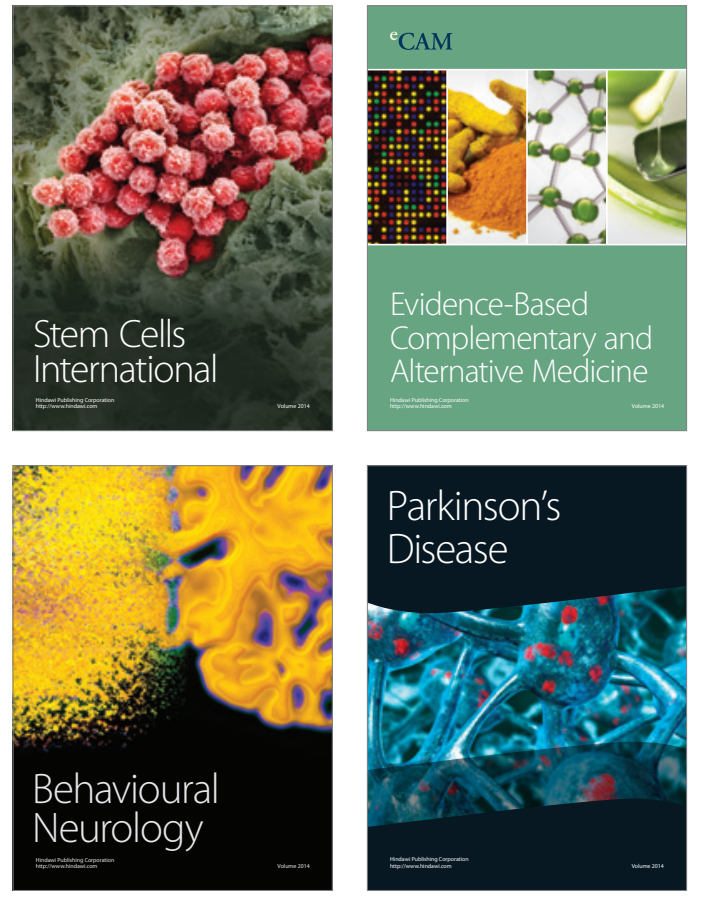
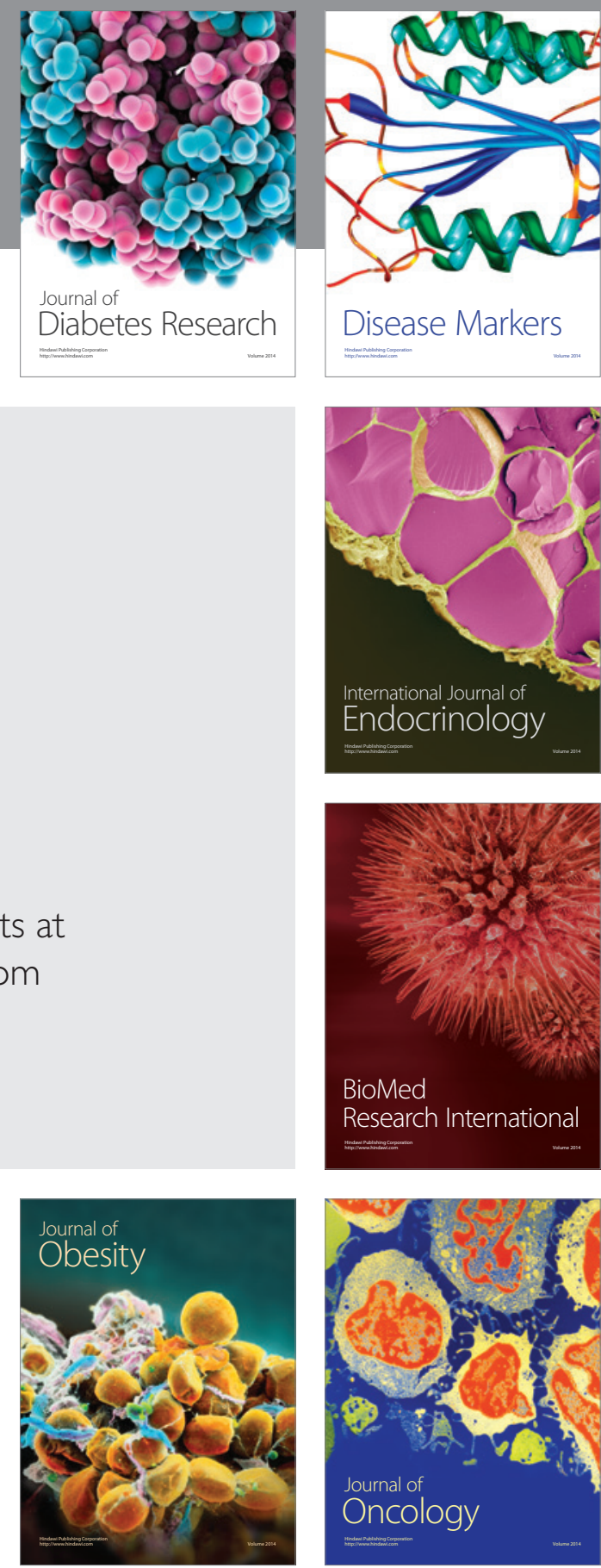

Disease Markers
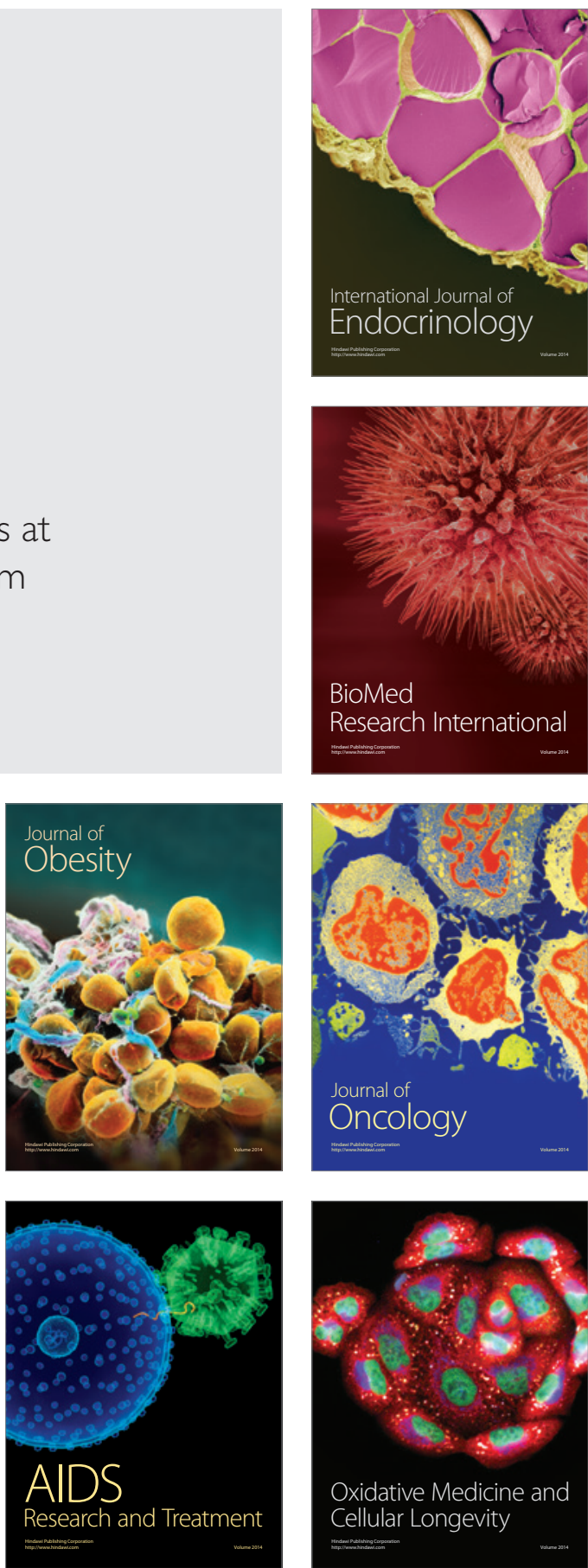